\title{
A review of the fate of engineered nanomaterials in municipal solid waste streams
}

\begin{abstract}
Florian Part ${ }^{a}$, Nicole Berge ${ }^{b^{*}}$, Paweł Baran ${ }^{c}$, Anne Stringfellow ${ }^{d}$, Wenjie Sun ${ }^{e}$, Shannon Bartelt-Hunt ${ }^{f}$, Denise Mitrano ${ }^{g}$, Liang $L^{b}$, Pierre Hennebert ${ }^{h}$, Peter Quicker ${ }^{c}$, Stephanie C. Bolyard', and Marion Huber-Humer ${ }^{2}$
\end{abstract}

\footnotetext{
${ }^{a}$ Department of Water-Atmosphere-Environment, Institute of Waste Management, University of Natural Resources and Life Sciences, Muthgasse 107, 1190 Vienna, Austria

${ }^{b}$ Department of Civil and Environmental Engineering, University of South Carolina, 300 Main Street, Columbia, SC 29208, United States
}
${ }^{c}$ Unit of Technologies of Fuels, RWTH Aachen University, Wüllnerstraße 2, 52062 Aachen, Germany
${ }^{d}$ Faculty of Engineering and the Environment, University of Southampton, SO17 1BJ, Southampton, England

${ }^{e}$ Department of Civil and Environmental Engineering, Southern Methodist University, 3101 Dyer Street, Dallas TX 75205, United States

${ }^{f}$ Department of Civil Engineering, University of Nebraska-Lincoln, 1110 S. $67^{\text {th }}$ St., Omaha, NE 68182-0178, United States

${ }^{g}$ Process Engineering, Eawag, Swiss Federal Institute of Aquatic Science and Technology. Überlandstrasse 133, 8600 Dübendorf, Switzerland

${ }^{h}$ National Institute for Industrial and Environmental Risk Assessment (INERIS), BP 33, 13545 Aix-en-Provence Cedex 4, France

${ }^{i}$ Environmental Research \& Education Foundation, 3301 Benson Drive, Suite 101, Raleigh, NC 27609, United States

*Corresponding author: Phone: (803) 777-7521; Fax: (803) 777-0670; email: berge@engr.sc.edu 
Abstract

Significant knowledge and data gaps associated with the fate of product-embedded engineered nanomaterials (ENMs) in waste management processes exist that limit our current ability to develop appropriate end-of-life management strategies. This review paper was developed as part of the activities of

59 the IWWG ENMs in Waste Task Group. The specific objectives of this review paper are to assess the 60 current knowledge associated with the fate of ENMs in commonly used waste management processes, 61 including key processes and mechanisms associated with ENM fate and transport in each waste 62 management process, and to use that information to identify the data gaps and research needs in this area.

63 Literature associated with the fate of ENMs in wastes was reviewed and summarized. Overall, results from

64 this literature review indicate a need for continued research in this area. No work has been conducted to 65 quantify ENMs present in discarded materials and an understanding of ENM release from consumer 66 products under conditions representative of those found in relevant waste management process is needed. 67 Results also indicate that significant knowledge gaps associated with ENM behaviour exist for each waste 68 management process investigated. There is a need for additional research investigating the fate of different 69 types of ENMs at larger concentration ranges with different surface chemistries. Understanding how 70 changes in treatment process operation may influence ENM fate is also needed. A series of specific research questions associated with the fate of ENMs during the management of ENM-containing wastes have been identified and used to direct future research in this area.

Keywords: engineered nanomaterials; waste management; landfills; recycling; incineration; biological 76 treatment 
Escalating production and subsequent incorporation of engineered nanomaterials (ENMs) in consumer products increases the likelihood of their release to the environment. ENMs including titanium dioxide 83 (nano- $\mathrm{TiO}_{2}$ ), zinc oxide $(\mathrm{ZnO})$, silver (nano-Ag), gold (nano-Au), $\mathrm{C}_{60}$ fullerenes, carbon nanotubes (CNTs), 84 graphite, and silica (nano- $\mathrm{SiO}_{2}$ ) have been incorporated in several commercially-available and commonly discarded products, including plastics, inkjet printer ink, textiles, cosmetics, sunscreens, cleaning materials, and sporting goods (Hansen et al. 2016; Lesyuk et al. 2015). The increased use of ENM-containing products warrants an immediate understanding of potential adverse effects ENMs may impart to the environment and human health (Mahaye et al. 2017; Mattsson and Simkó 2017; Musee 2017; Schaumann et al. 2014; Valsami-Jones and Lynch 2015). As ENM-containing products reach the end of their useful life, the development of appropriate end-of-life management strategies is critical to minimize human and/or environmental exposure. Several modelling-based studies describing different aspects of discarded ENMs and their fate in the environment (e.g., Boldrin et al. 2014; Caballero-Guzman et al. 2015; Keller et al. 2013; Mueller et al. 2013; Mueller and Nowack 2008; Sun et al. 2016; Sun et al. 2014; Suzuki et al. 2018b; Walser and Gottschalk 2014) highlight the important role different waste management processes may play in ensuring appropriate and adequate disposal of ENM-containing products.

Significant knowledge and data gaps associated with the fate of ENMs during waste management processes exist that limit our current ability to develop appropriate end-of-life management strategies. A fairly limited number of laboratory and field-scale studies evaluating the release and/or environmental fate of ENMs from discarded materials in conditions representative of waste management processes have been conducted (e.g., Bolyard et al. 2013; Bouillard et al. 2013; Lozano and Berge 2012; Ounoughene et al. 2015; Walser et al. 2012). However, very little knowledge exists about the mass of ENMs discarded, the transfer of ENMs from their parent products during waste management, and the fate and transport of ENMs during 103 incineration, composting, recycling, and landfilling processes. Understanding ENM behaviour in these 104 processes is complicated by the lack of analytical techniques to detect ENMs in the complex solid, liquid, 105 and gaseous matrices associated with these processes (Laborda et al. 2016; Mackevica and Foss Hansen 106 2016; Part et al. 2015; Reinhart et al. 2016). 
In response to this emerging management challenge, in 2014 the International Waste Working Group (IWWG) formed the Task Group on Engineered Nanomaterials in Waste. The members of this task group include experts in the areas of waste management and nanomaterial fate and transport. The purpose of this task group is to serve as a technical resource on issues associated with the end-of-life management of ENM-containing wastes. The ultimate goal of this task group is to develop guidance on the appropriate end-of-life management strategies for these materials.

specific objectives associated with this review paper are to assess the current knowledge associated with the fate of ENMs in commonly used waste management processes, including key processes and mechanisms associated with ENM fate and transport in each waste management process, and to use that information to identify data gaps and research needs in this area. Currently available literature associated with ENMs embedded within waste products, the potential for release of ENMs from these products, and their potential fate during waste degradation (e.g., composting), recycling, incineration, and landfilling was assessed and reviewed.

\section{Review Scope and Methods}

Generally, nanomaterials are defined as materials that have at least one external dimension or surface structure in the nanoscale (i.e. from, 1 to $100 \mathrm{~nm}$ ). ENMs are defined as nanomaterials designed for a specific purpose or product (ISO/TS 80004-1:2015). The focus of this review paper is on understanding the current knowledge associated with the fate of ENMs in solid waste treatment processes (e.g., composting, recycling, incineration, and landfilling). Because this review focuses specifically on the fate of ENMs during waste management processes, this review does not differentiate between a product that may be specifically classified as a nanowaste according to previously published definitions of this special type of waste provided by Boldrin et al. (2014) and Musee et al. (2011b). Musee et al. (2011b) define nanowaste as "waste stream(s) containing ENMs, or synthetic by-products of nanoscale dimensions, generated either during production, storage and distribution, or waste stream(s) resulting from the end of a lifespan of formerly nanotechnologically enabled materials and products, or items contaminated by ENMs such as pipes, 133 personal protection equipment, etc", while Boldrin et al. (2014) define nanowaste as "only separately collected or collectable waste materials which are or contain ENMs. This means that nanowaste can include 
135 (1) ENMs as a single fraction, e.g. by-products from manufacturing of nanoproducts, (2) end-of-life (EOL) 136 nanoproducts and (3) individual waste materials contaminated with ENMs, for example, sludge from wastewater treatment." In this review, the source of ENMs may be from any discarded materials (e.g., consumer products, manufacturing wastes, biosolids, contaminated products, such as personal protection equipment) and is therefore generally referred to as "ENM-containing wastes." Additionally, nanomaterials generated as an unintentional by-product of a process ("incidental nanomaterials" or "ultrafine particles", such as nanoscale soot particles) or nanomaterials that are unintentionally released to the environment are defined as "nanoemissions". On the contrary to nanowastes, whose origin can be attributed to

143 ENM-containing items, nanoemissions can stem from both EOL ENM-containing and ENM-free products

144 (e.g., as nanoscale debris). Nanoemissions can be caused by physical, chemical, biological, and/or thermal 145 stresses resulting from certain processes or waste treatment operations. Figure 1 illustrates 146 ENM-containing waste generation and potential nanoemissions along the entire value chain of ENMs. 147 Although not detailed in this study, it is important to note that waste management processes may generate nanoemissions of naturally occurring nanomaterials (e.g., particulate matter or ultrafine particles during 149 incineration, originally stemming from biogenic waste).

Although this review paper focuses on the behaviour of ENMs during specific waste management processes, it is important to note that the regulations and practices governing waste management differ significantly from country to country. The purpose of this review is not to provide details associated with country-specific waste management practices and regulations. Therefore, the discussion of ENM fate during each waste management process described within this review may not be applicable to all geographic regions. It is also important to note that the inclusion or exclusion of specific waste management processes described in this review is not meant to reflect any preference or to advocate for the use of specific waste management processes. Instead, this review is meant to only report on the state of the current knowledge associated with the fate of ENMs during waste management.

In this review, primarily peer-reviewed literature was identified by performing searches in professional search engines and databases (e.g., Science Direct, Web of Science, Google Scholar) with combinations of 161 the following keywords: nanomaterial, nanoparticle, composting, biodegradation, landfill, leachate, 162 incineration, combustion, release, municipal solid waste, wastewater, biosolids, transport, and consumer 
product. Collected literature for each waste management process was then reviewed and used to assess

164 the current knowledge associated of the fate of ENMs and to identify data gaps and research needs.

\section{ENMs in Consumer Products}

Discarded ENM-containing consumer products likely represent the largest contribution of ENMs in waste streams. It should be noted, however, that no laboratory or field-scale studies that have specifically identified or quantified the type or amount of ENMs present in discarded wastes that exist. ENM release during the active life of each ENM-containing product will influence the amount of discarded ENMs. Table 1 provides a review of different types and classes of ENMs that are commonly found in consumer products. The purpose of this section is to review information known about the ENM content of consumer products, as described in currently available databases, and to review what is currently known with respect to ENM release from consumer products during both their active and post-disposal life.

\subsection{Nano-enabled product composition}

The immense growth of nanotechnology has led to the need for resources that enable consumers, policy makers, and regulators to research products in the consumer marketplace. As a result, a series of databases detailing the ENM content of consumer products were developed. Information provided in these databases allows a thorough investigation of the types and amounts of ENMs that may ultimately end up in waste streams (Heggelund et al. 2016). The longest established open access database, the Consumer Products Inventory (CPI), was created in 2006 in the U.S. as part of the Project on Emerging Nanotechnologies (Rejeski 2009). This database was last updated in 2015, as outlined by Vance et al. (2015). Each entry in this database lists the name of the product, the country of origin, the type of ENM, and a classification (1 to 5) that gives an indication of the level of confidence in manufacturers or retailers information about the ENM content of the product (e.g., if there are datasheets available for the ENM characteristics). This inventory lists entries under eight consumer goods categories: health and fitness, home and garden, automotive, electronics, food and beverage, appliances, children's goods, and a cross-cutting sector (including coatings and bulk silver nanoparticles). At the time, the database was accessed (January 2018), the health and fitness category contained the most entries (908), followed by items for the home and garden (356), and automotive goods (214). The CPI database is searchable by 
category, nanomaterial function (e.g., lubricant, pigment), the location of the ENM in the product (e.g., surface bound on a solid or suspended in liquid), and potential pathway to human exposure. Understanding the ENMs found in different product categories facilitates the development of potential disposal and end-of-life scenarios for ENM-containing wastes (e.g., food wastes may be composted, children's goods likely end up in household waste bins and, depending on the country of waste generation, consequently discarded in landfills or incinerated).

The availability of ENMs in consumer products has increased significantly over the last decade; only 54 products were listed when the CPI database was initiated in 2005 (Rejeski 2009), whereas in 2018 (accessed in January) about 1,800 products were listed. More recently, The Nanodatabase (nanodb.dk) was developed in Denmark and contains an inventory of European products containing ENMs. The Nanodatabase uses the same categories as the CPI and presents assessments of products detailing nanostructure of the material, exposure pathway, and likely end-of-life waste fraction. Again, health and fitness products, home and garden and automotive goods dominate the product categories found in this database (Hansen et al. 2016). Since The Nanodatabase was created in 2012, the number of products listed has grown from about 1,200 to approximately 3,000 (accessed January 2018). This constantly updated database includes important basic data that can be used to estimate and model ENM distribution in waste streams (Heggelund et al. 2016).

Approximately half of the products listed in the CPI and The Nanodatabase identify which ENMs are present, but rarely describe the mass or concentration of each contained within the products. Metals and metal oxides form the most common ENMs identified in the CPI, with nano-Ag being most frequently found, followed by nano-Ti and then -Zn. Carbon black and single and multiwalled CNTs are the most frequently listed carbonaceous materials. Some products list multiple ENMs (e.g., nano-Ag or -Zn may be combined with nano- $\mathrm{TiO}_{2}$ ). In the Nanodatabase, nano-Ag is also the most frequently reported, followed by nano- $\mathrm{TiO}_{2}$; however, the proportion of nano-Ag in the Nanodatabase is less than in the $\mathrm{CPI}$, whereas nano- $\mathrm{TiO}_{2}$ is more frequently reported in the Nanodatabase. This reflects the global variations in availability of ENMs (Hansen et al. 2016). Zhang et al. (2015) evaluated approximately 1,400 products in the Singapore retail market. Nanoparticles (NPs) were confirmed or likely in $30 \%$ of consumer products tested, the largest categories being food and health and fitness products, and the predominant particles were nano-SiO 
219 that nano- $-\mathrm{TiO}_{2}$ and $-\mathrm{SiO}_{2}$ were most commonly used (Schmid and Riediker 2008). The same applies to the 220 Japanese construction sector (Suzuki et al. 2018b).

221 Despite the increasing amount of data available, it is difficult to obtain an accurate picture of the quantity of ENMs in production or circulation. While inventories and databases list the types of products and the nanomaterial present, there is little information about the mass or concentration of individual ENMs in particular items. Market reports for 2012 estimated global production of the most frequently used ENMs to be up to 320,000 tonnes/year (Keller and Lazareva 2014). But other studies have reported much lower values. A survey of industrial experts conducted in 2010 reported median global production and utilisation of nano- $\mathrm{SiO}_{2}$ of 5,500 t/a, nano- $\mathrm{TiO}_{2}$ 3,000 t/a, and CNT $300 \mathrm{t} / \mathrm{a}$ (Piccinno et al. 2012). These values are at least an order of magnitude lower than those in market reports, however, there was considerable variation in the estimates obtained in the survey. It was also noted in the study that responses were often compromised by the lack of a global definition of differently applied survey methods and of what constitutes an ENM, especially where materials comprise agglomerations of nano-sized particles (Piccinno et al. 2012). Hendren et al. (2011) estimated the total mass of nano- $\mathrm{TiO}_{2},-\mathrm{Ag},-\mathrm{CeO}_{2}, \mathrm{CNT}$ and fullerenes production in the U.S. obtaining lower and upper bounds of 8,000 and 40,000 t/a, respectively. The authors highlighted the difficulties in reaching these values due to the inconsistency of available data and the lack of information on production volumes.

The ENM market is dynamic. The growth in the number of different types of products has been noted above and similarly, the mass of different materials is likely to change rapidly with time (Greßler and Gazsó 238 2014). It is anticipated that as requirements for reporting concentrations and types of ENMs found in consumer products are implemented, this information will also influence our knowledge on ENM-containing products and will aid in predicting ENM distribution in the environment by using material flow models (Suzuki 241 et al. 2018b). Greßler and Gazsó (2014) reported that labelling requirements according to the latest 242 amendment of the European Regulation (EC) No 1223/2009 () on cosmetic products has led to a rapid 243 increase of registered ENM-containing cosmetics. In summary, it is imperative that more accurate 244 information on the global quantity of ENMs, their mass and characteristics (e.g., size, shape, crystallinity, 
surface area, charge, specific surface properties, Part et al. (2015)) in individual consumer items be made

246 available to enable more accurate ENM flow and transport modelling.

\subsection{ENM release and Distribution}

There are reviews that have highlighted the paucity of studies on release of ENMs from products during consumer use, in comparison to more extensive research on ENM hazards and exposure (Froggett et al. 2014; Mackevica and Foss Hansen 2016). There are many individual types of ENMs, used in many different products, and employed in many different ways, resulting in relatively few studies that can be directly compared. ENM release during use (also known as the "active life") may be due to weathering in the environment or human activity. Nanoforms may be released as discrete units, as self-agglomerations, combined with the product matrix, or bound to environmental substances (Musee 2011a). Both discrete and bound forms may be weathered by chemical or physical processes during use. Release of these different forms of ENM may not be directly comparable to release of discrete particles (Lowry et al. 2012b; Nowack et release of ENMs under different use scenarios. These four ENMs are considered below to illustrate different loss pathways and transformations, which may occur during use.

Table 1 shows that Nano-Ag, $-\mathrm{TiO}_{2},-\mathrm{SiO}_{2}$, and CNTs is found in many different consumer products. Below, selected case studies are summarized focusing on the release of these most frequently used ENMs during their use phase. Studies on the release of nano-Ag have primarily focused on textiles. Results from washing with distilled water demonstrated release of ionic Ag from antibacterial socks, but also some loss of nano-Ag re-agglomerates (Benn et al. 2010; Benn and Westerhoff 2008b; Mitrano et al. 2014; Pasricha et al. 2012). Geranio et al. (2009) demonstrated that washing textiles containing nano-Ag at a high pH and in the presence of an oxidant resulted in the release of ionic $\mathrm{Ag}$ and $<450 \mathrm{~nm}$ particles, whereas washing in detergent without bleach, loss of ionic $\mathrm{Ag}$ was limited and particles were $>450 \mathrm{~nm}$, probably due to mechanical abrasion. Multiple species of Ag may be present in textiles due to manufacturing techniques or due to environmental exposure during storage or use. For example, reduction of nano- $\mathrm{Ag}$ to $\mathrm{Ag}_{2} \mathrm{~S}$ is likely to occur in sulphur-rich environments (Lombi et al. 2013a; Mitrano et al. 2016). The presence of multiple nano-Ag species in original textiles and the different coatings (e.g., citrate, polymers, polysaccharides) used 
273

274

275

276

277

278

279

280

281

282

283

284

285

286

287

288

289

290

291

292

293

294

295

296

297

298

299

difficult to predict the amount, size, and type of species released during washing and those remaining in the washed textile (Lombi et al. 2013a; Lorenz et al. 2012; Mitrano et al. 2016).

Personal care products, frequently containing nano- $\mathrm{TiO}_{2}(\mathrm{Table} 1)$, are predominantly disposed to wastewater treatment plants (WWTPs) (96-98\% in a U.S. survey (Keller et al. 2014)), although some materials are discarded in landfills. Keller et al. (2014) estimated that 870-1000 tonnes/year nano- $\mathrm{TiO}_{2}$ discarded of by these routes. Studies on the environmental release of photocatalytic nano- $\mathrm{TiO}_{2}$ embedded in paint and coatings via weathering by UV-light and rainfall in natural and laboratory simulations have been conducted (Al-Kattan et al. 2013; Al-Kattan et al. 2014; Kaegi et al. 2008; Olabarrieta et al. 2012). Results from these studies suggest that only limited losses of nano- $\mathrm{TiO}_{2}$ occurred, suggesting the ENMs were strongly bound to the matrix, but $\mathrm{TiO}_{2}$ agglomerates were released by photodegradation of the matrix and/or mechanical separation of nano- $\mathrm{TiO}_{2}$ particles (Al-Kattan et al. 2013; Olabarrieta et al. 2012).

As with nano- $\mathrm{TiO}_{2}$, the nano- $\mathrm{SiO}_{2}$ (Table 1) used in cosmetics and drugs are transported to wastewater treatment plants (WWTPs) during use (Keller et al. 2014). Weathered and leached paints may release small amounts of nano- $\mathrm{SiO}_{2}$ as individual particles, or as agglomerates together with the paint matrix; photodegradation of surface coatings can expose nano- $\mathrm{SiO}_{2}$ below making it susceptible to removal by abrasion (Al-Kattan et al. 2015; Nguyen et al. 2012; Sung et al. 2015; Zuin et al. 2013). Nano- $\mathrm{SiO}_{2}$ release is also affected by the type of paint binder used (Wohlleben et al. 2011; Zuin et al. 2014).

There are many combinations of CNTs and other compounds (e.g., epoxy, polycarbonate, polyamide) used in consumer products. Laboratory weathering studies have shown that CNT composites are susceptible to photodegradation to varying degrees, but these processes primarily affect the matrix (Kingston et al. 2014; Köhler et al. 2008; Nguyen et al. 2012; Wohlleben et al. 2014). If the matrix surface is damaged by photodegradation, loss of CNTs, even with subsequent abrasion, appears to be very low, although more research is needed (Kingston et al. 2014; Petersen et al. 2014; Rhiem et al. 2016; Schlagenhauf et al. 2015). In textiles, pure CNT yarns may be combined with other components during fabric manufacturing. While CNT yarns are relatively stable, degradation of combined polymers due to chemical or physical effects (e.g., oxidation, high temperature, humidity, UV radiation) may occur, and/or physical abrasion may result in the loss of textile fibers containing CNTs (Köhler et al. 2008). 
Despite the lack of information on the quantity of ENMs entering the marketplace and the limited availability of data on release mechanisms, rates and transport pathways during use, important information can be obtained from results associated with ENM flow modelling studies. A range of approaches have been taken from early deterministic models (Mueller and Nowack 2008) to probabilistic models (Gottschalk et al. 2011; Gottschalk et al. 2010; Gottschalk et al. 2009b). These studies have concentrated on a number of different ENM types in consumer items, such as textiles (Wigger et al. 2015), personal care products and paints (Arvidsson et al. 2012; Keller et al. 2014; Musee 2011b; Musee 2011c; Musee 2017) or in the construction sector (Hincapié et al. 2015; Suzuki et al. 2018b). Some of the ENM flow models were applied for single countries, such as South Africa (Musee 2011c; Musee 2017), Denmark (Gottschalk et al. 2015; Heggelund et al. 2016), Austria (Part et al. 2017), Switzerland (Caballero-Guzman et al. 2015; Gottschalk et al. 2011; Hincapié et al. 2015), Japan (Suzuki et al. 2018b), or for different regions (e.g., the EU and the U.S.), or even globally (Adam and Nowack 2017; Gottschalk et al. 2009a; Keller et al. 2014; Mueller and Nowack 2008; Song et al. 2017). For example, probabilistic modelling was used to model the flow of metal oxides, nano-silver, CNTs, quantum dots, and carbon black (Gottschalk et al. 2015). Results from this study suggest that photostable nano- $\mathrm{TiO}_{2}$ used in cosmetics likely first enter a wastewater treatment plant and then partition into the sludge, which may then be ultimately applied to soil. Photocatalytic nano- $\mathrm{TiO}_{2}$ used in construction materials likely enters either recycling processes or landfills. This study also indicated that CNTs predominantly enter recycling processes, waste incineration, or landfills. This is also in accordance with the dynamic ENM flow model by Suzuki et al. (2018a), who focused on the end of life phase of ENM-containing construction materials in Japan. Their model predicted that, in 2016 , about $40-47 \%$ of end of life ENMs ended up in recycled materials, $36-41 \%$ in landfills, and 5-19\% were likely to diffusely release into soils, surface waters or the atmosphere. The review of modelling studies by Caballero-Guzman and Nowack (2016) note that many problems resulting from the paucity of data has led to the use of many assumptions and extrapolations. As described previously, efforts to improve the data made available by manufacturers is needed.

\section{Biological treatment of ENM-containing wastes}


biological treatment of wastes is also important when considering end-of-life management strategies for ENM-containing wastes (e.g., consumer products, biosolids). Aerobic and anaerobic treatment of waste and its subsequent land application is not allowed in every country and is generally only allowed when it fulfils certain compost criteria (e.g., regarding heavy metal content, electric conductivity, pH etc.). In some countries, mixed MSW may be stabilized under aerobic conditions (mechanical-biological pre-treatment) and subsequently landfilled. In many other countries, composting of mixed MSW or direct land applications of biogenic wastes or biosolids from WWTPs are tolerated. It should be noted, as stated previously, that the purpose of this review is not to provide an overview of the waste management regulations associated with each country.

To date, little work has been conducted to understand implications associated with the treatment of biodegradable ENM-containing wastes under both aerobic and anaerobic conditions. Specific fate and biodegradation experiments have only been conducted at the laboratory-scale and in the presence of somewhat limited types and concentrations of ENMs, with the majority of studies reporting on nano-SiO ${ }_{2}$, $-\mathrm{ZnO}$, and in the case of biobased nanocomposites (e.g., with nanoclays). Biodegradable ENM-containing consumer products likely to be treated via biodegradation includes a variety of food and beverages, food-related packaging materials (e.g., plastics, paper), and textiles (Table 2), representing a range of ENM types. Biosolids or sewage sludge originating from WWTPs represent another potentially large source of

345 ENMs entering these processes. ENMs present in wastewater, including, nano- $\mathrm{TiO}_{2},-\mathrm{Ag},-\mathrm{ZnO},-\mathrm{SiO}_{2}$, and fullerenes $\left(C_{60}\right)$, have been documented to accumulate in biosolids (Kiser et al. 2009; Wang et al. 2012; Westerhoff et al. 2013). It is important to note that approaches to biosolids treatment are very

348 country-specific. For example, direct land application of biosolids from WWTPs are avoided in countries 349 such as Austria, Switzerland, and Germany, where sewage sludge needs to be thermally pre-treated. 350 Therefore, some ENM-related studies focussing on the incineration of biosolids are discussed in more detail 351 in Section 6. On the contrary, direct land application of biosolids that may contain ENMs are commonly 352 conducted in many other countries.

\subsection{Potential ENM fate and transformation during aerobic conditions}

Currently, the majority of studies evaluating the compostability of ENM-containing wastes focus on 
laboratory-scale. Such studies have been primarily conducted on different biodegradable polymers representing potential food packaging materials containing a variety of ENMs (e.g., clays, silver, cellulose), with a concentration on poly(lactic acid) bio-nanocomposites (e.g., Bitinis et al. 2013; Fortunati et al. 2014; Fukushima et al. 2009). Results from these studies suggest that ENM presence does not negatively influence bio-nanocomposite degradation/disintegration processes and, in some instances, enhances such processes (e.g., Abreu et al. 2015; Balaguer et al. 2016; Maiti et al. 2007; Ramos et al. 2014; Ray et al. 2003a; Ray et al. 2003b; Stloukal et al. 2015). Similar results from the composting of nano-fiber reinforced bio-copolyester composites have been reported (Maiti et al. 2012).

Fewer studies evaluating the fate and influence of nano- $\mathrm{ZnO}$ and -Ag during composting of biosolids have been conducted (Lombi et al. 2013b; Lombi et al. 2012; Ma et al. 2014). Collectively, transformations of ENM surfaces during composting were observed in all studies. Lombi et al. (2012) report that zinc speciation shifts towards complexation with phosphate and iron during composting, with nanoparticle hydrophobicity slowing down such transformations. Ma et al. (2014) report similar results associated with nano-ZnO during aerobic composting, with exact speciation depending on the nature (e.g., oxic or reduced) of the biosolids. Lombi et al. (2013b) reported that following biosolids post-processing, nano-Ag particles transformed to stable $\mathrm{Ag}_{2} \mathrm{~S}$ that remained stable over a six-month period; such transformations were not influenced by nano-Ag composition and/or surface functionality.

The influence of nano-Ag and nano- $\mathrm{TiO}_{2}$ presence during the aerobic composting of MSW has also been investigated over a large range of ENM concentrations (Table 3). The majority of these studies indicate that the presence of nano-Ag or $-\mathrm{TiO}_{2}$ at the concentrations investigated do not inhibit waste degradation processes at concentrations as high as 2,250 mg Ti/kg organic matter and $100 \mathrm{mg} \mathrm{Ag} / \mathrm{kg}$ wet waste (Table 3). One exception to this observation is a study conducted by Zhang et al. (2017). Zhang et al. (2017) suggested that nano-Ag may impede organics decomposition. Other aspects of the composting process 379 may also be influenced. Gitipour et al. (2013) evaluated the influence and fate of nano-Ag during the composting of MSW. Simulated food waste was spiked with a concentration of $2 \mathrm{mg} / \mathrm{kg}$ of polyvinylpyrrolidone (PVP) coated nano-Ag and aerobically composted over a 60 -day period at $50^{\circ} \mathrm{C}$ and a moisture content of $65 \%(\mathrm{w} / \mathrm{w})$. Results from this study indicated that the presence of nano-Ag did not 383 influence the solid, liquid, or gas quality parameters and thus overall composting performance, relative to the 
control. The presence of the ENMs, however, did result in changes in bacterial community structure. Low concentrations of $\mathrm{Ag}$ species were detected in the leachate, while the total $\mathrm{Ag}$ concentration in the solids was significant, suggesting the majority of $\mathrm{Ag}$ was either adsorbed or complexed with the solid natural organic matter, similar to that observed with biosolids during wastewater treatment processes.

388 Transformations of dissolved $\mathrm{Ag}$ ions and nano- $\mathrm{Ag}$ particle surfaces to $\mathrm{AgCl}$ and/or $\mathrm{Ag}_{2} \mathrm{~S}$ during the composting process were also observed, potentially reducing ENM mobility and toxicity. Yazici Guvenc et al. (2017) also reported that leachate $\mathrm{pH}$, ionic strength, and complex formation with chloride may reduce the potential nanomaterial toxicity effects. Zhang et al. (2017) reported that nano-Ag may influence the fate of nitrogen during composting, ultimately reducing losses of total nitrogen. Gitipour et al. (2013), however, indicated there were no statistically significant difference associated with nitrogen fate during composting when in the presence of nano-Ag at similar concentrations.

Although these studies provided an initial framework for understanding ENM fate during composting, additional research investigating a greater range of ENM types, concentrations, and surface chemistries (e.g., pristine and with a variety of surface capping agents), solid organic composition, aeration rates, and moisture contents is needed.

\subsection{Land application of compost and biosolids}

Compost and biosolids, in some countries, is sometimes land applied. Therefore, there is a need to understand the fate of ENMs in this compost and biosolids to determine whether release of ENMs from these materials may pose a threat to the local ecosystem. There is little information known about the fate of ENMs following land application of these materials. Leaching of ENMs from these materials is a possible route for ENM release to the environment. Stamou and Antizar-Ladislao (2016a) conducted leaching studies from compost containing commercially doped nano- $\mathrm{TiO}_{2}$ and -Ag. Results from these experiments indicate that only $5 \%$ of the nano- $\mathrm{Ag}$ and $15 \%$ of the nano- $\mathrm{TiO}_{2}$ were released from the compost, suggesting that if land applied, the ENMs may accumulate in the top layers of the soil. This is consistent with Colman et al. (2013); they reported that the majority of applied Ag, independent of the applied form (ENM or silver nitrate salt), were found in surface soils (depths of $0-1 \mathrm{~cm}$ ) with measured concentrations that were decreasing with 410 soil depth. Yang et al. (2014b) identified the presence of nano- $\mathrm{TiO}_{2}$ particles in the first $30 \mathrm{~cm}$ of agricultural 411 sites that applied biosolids over a long-period of time. Based on a life-cycle assessment (LCA) study, the 
412 impact of the accumulated nano-Ag reportedly had a significant impact on the terrestrial ecotoxicity and 413 human toxicity (Stamou and Antizar-Ladislao 2016b).

414 Land application of these materials containing ENMs may also influence plant growth/yield and soil microbial systems. Generally, results from studies investigating the influence of land application of biosolids 416 containing ENMs or soils amended with ENMs (e.g., Chen et al. 2015; Colman et al. 2013; Judy et al. 2015; 417 Judy et al. 2012; Priester et al. 2012) suggest that the application of ENMs may influence plant growth/yield 418 and soil microbial systems. Accumulation of ENMs within plants has been observed, but ENM location within 419 the plant may depend on ENM type. Priester et al. (2012) conducted a study in which soybean plants were 420 grown in soil amended with pristine nano- $\mathrm{ZnO}(0.05-0.5 \mathrm{~g} / \mathrm{kg})$ and nano- $\mathrm{CeO}_{2}(0.1-1 \mathrm{~g} / \mathrm{kg})$. Results from 421 this study indicated that zinc was taken up and distributed through the edible parts of soybean plants, while 422 the nano- $\mathrm{CeO}_{2}$ particles were found in the plant roots and root nodules. These results were consistent with 423 studies reported by others (e.g., Colman et al. 2013; Judy et al. 2015; Judy et al. 2012).

\subsection{Potential ENM influence on microbial processes during biological treatment}

To date, there are many studies that have been performed to understand the ecotoxicology of ENM on biodegradation processes and their uptake and/or accumulation pathways to microbes, including ENMs likely found in landfills and composting facilities. However, very few of these studies have investigated these processes in conditions closely simulating these processes. Extensive research has suggested that ENMs pose adverse and toxic effects to microbes (Baun et al. 2008; Brunner et al. 2006; Demirel 2016; Louie et al. 2016; Mahaye et al. 2017; Rocha et al. 2017; Schaumann et al. 2014). Based on the current toxicity studies available, several mechanisms for ENM toxicity have been proposed, including: sorption to the surface and cell uptake (Khanna et al. 2015; Limbach et al. 2007), dissolution of toxic ions (Brunner et al. 2006), translocation to target organs, oxidation of cell compounds and generation of reactive oxygen species (ROS) (Kim et al. 2010; Stark 2011) (Khanna et al. 2015). The influence of ENMs on biological processes may be different in aerobic and anaerobic systems, depending on specific physical-chemical properties of 437 ENMs. For examples, some ENMs (i.e., nano-CuO and $-\mathrm{Mn}_{2} \mathrm{O}_{3}$ ) can cause ROS-dependent protein 438 oxidation as the mechanism of nanotoxicity under aerobic conditions; however, oxidation of protein can also 439 be attributed to direct contact with some ENMs (i.e., nano- $\mathrm{Cu}^{0}$ and $-\mathrm{CuO}$ ) or their corrosive products (e.g., 
440 soluble $\mathrm{Cu}^{2+}$ ions) without the involvement of ROS in the anaerobic system (Gonzalez-Estrella et al. 2015;

441 Gonzalez-Estrella et al. 2013; Otero-González et al. 2014; Sun et al. 2013). Therefore, this section contains

442 a general discussion on ENM influence on waste biodegradation that may occur during composting or in

443 anaerobic conditions (e.g., landfills, anaerobic digestion).

$444 \quad$ Nano-Ag is known to possess antibacterial properties, where the widely accepted mechanism is 445 attributed to the release of soluble $\mathrm{Ag}$ ions on the particle surface. These ions are known to inhibit the 446 enzymes of bacteria, for example nitrifying (Ratte 1999) and denitrifying bacteria (Throback et al. 2007) and 447 methanogenesis (Yang et al. 2012), block DNA transcription and interrupt bacterial respiration and 448 adenosine triphosphate (ATP) synthesis (Kumar et al. 2005). In general, nano-Ag and their ionic 449 counterparts demonstrate different mechanism and levels of toxicity when exposure to microorganisms in 450 diverse environments. Ag ions have a great propensity to bioconcentrate in organisms, since the chemical 451 properties of the $\mathrm{Ag}$ ions make them compatible for uptake via cell membrane ion transporters (Luoma 2008). In comparison, nano-Ag is smaller than the largest pore and can pass through the cell wall and reach the plasma membrane. For example, the transmission electron microscopy (TEM) analysis showed that nano-Ag penetrated through living semi-permeable membranes of bacteria (Fabrega et al. 2009; Xu et al. 2004). Choi and $\mathrm{Hu}(2008)$ found out that nano-Ag demonstrated much more effective suppression than $\mathrm{Ag}$ ions on the growth of autotrophic nitrifying bacteria of a WWTP community. In addition, Choi et al. (2008) further reported that the polyvinyl alcohol (PVA) coated nano-Ag particles showed a stronger ability to inhibit the autotrophic microorganism, whereas Ag ions are toxic to heterotrophic species. Moreover, Yang et al. (2012) demonstrated that exposure to nano-Ag at a concentration of $10 \mathrm{mg} / \mathrm{Kg}$ or higher led to inhibition to methanogenesis and biogas production in a simulated landfill bioreactor. Compared to the aqueous phase, the toxicity of $\mathrm{Ag}$ to microorganisms in soil, sewage sludge or sediments is very low, mainly due to low bioavailability of $\mathrm{Ag}$ in the form of $\mathrm{Ag}_{2} \mathrm{~S}$.

Cu-based $\left(\mathrm{Cu}^{0}\right.$ and $\left.\mathrm{CuO}\right)$ ENMs also have potentially inhibitory effects to the different key microbial 464 trophic groups involved in biological wastewater treatment processes (Gonzalez-Estrella et al. 2015; 465 Gonzalez-Estrella et al. 2013; Otero-González et al. 2014). In particular, nano-Cu inhibits methanogens, 466 which is, for example, the dominant microbial activity under anaerobic conditions. In addition, the results 467 strongly indicated that the inhibition associated with the uncoated nano-Cu was mainly due to the release of 
soluble toxic $\mathrm{Cu}^{2+}$ ions by ENM corrosion and dissolution, which is similar to the toxic mechanism of 469 nano-Ag. Thus, the results indicated that the toxic effects of ENMs that have high solubility, are attributed to 470 not only the direct contact and/or uptake of the ENM itself, but also the enhanced release of soluble and 471 toxic ions due to the nanosized properties.

472 Some studies have also shown that nano- $\mathrm{ZnO}$ exerts higher toxicity than nano- $\mathrm{TiO}_{2}$ to bacteria, algae, 473 and aquatic invertebrates (Heinlaan et al. 2008; Hsiao and Huang 2011; Mu et al. 2011; Xia et al. 2008; Yu 474 et al. 2015). Similar to nano-Ag and - $\mathrm{Cu}$, the toxicity of nano-ZnO is mainly attributed to the release of toxic $475 \mathrm{Zn}$ ions through the corrosion and dissolution of ENMs. Few studies demonstrated the toxic effect of 476 nano-ZnO on the reduction of biogas production from sludge digestion process (Nguyen et al. 2015) and 477 simulated bioreactor landfills (Temizel et al. 2017), however, Nguyen et al. (2015) showed the inhibition can 478 be overcome when the exposure concentration of nano-ZnO was in the tolerable range, such as 100 and $479500 \mathrm{mg} \mathrm{L}^{-1}$. Additionally, Mu et al. (2011) indicated that higher concentrations of nano-ZnO decreased the 480 activities of protease and coenzyme F420, and the abundance of methanogenesis Archaea. Furthermore, a 481 high dosage of nano-ZnO showed strong inhibition on denitrifying bacteria, including Diaphorobacter or 482 Thaueras, and those in the Sphaerotilusleptothrix group (Chen et al. 2014).

483 It is well known that nano- $\mathrm{TiO}_{2}$ has the antibacterial ability to diverse bacteria mainly due to both nanosized and photocatalytic properties (Durán et al. 2007; Fu et al. 2005). Zheng et al. (2011) showed that 485 the long-term exposure (70 days) to nano- $\mathrm{TiO}_{2}$ at $50 \mathrm{mg} \mathrm{L}^{-1}$ significantly inhibited the biological nitrogen 486 removal in an anaerobic-low dissolved oxygen (DO 0/15-0/50 $\mathrm{mg} \mathrm{L}^{-1}$ ) sequencing batch reactor operated 487 but phosphorus removal was unaffected. Additionally, Li et al. (2016) investigated the impact of nano- $\mathrm{TiO}_{2}$ 488 on the microbial denitrification activity and the microbial community structure. The results demonstrated that 489 increasing antibacterial activity is attributed to the increased production of ROS induced by nano- $\mathrm{TiO}_{2}$. 490 Furthermore, $\mathrm{Ge}$ et al. (2011) reported that nano- $\mathrm{TiO}_{2}$ and $-\mathrm{ZnO}$ negatively affected soil microbial biomass 491 and community diversity, in which nano- $\mathrm{ZnO}$ had more of an adverse effect than nano- $\mathrm{TiO}_{2}$. However, 492 several studies showed that exposure to nano- $\mathrm{TiO}_{2}$ did not show any inhibitory effects in terms of methane 493 generation under anaerobic digestion (Gonzalez-Estrella et al. 2013; Mu et al. 2011). It is well-known that 494 diverse anaerobic microbes show different levels of resistances to toxic substances. In this case, the toxicity 495 of nano- $\mathrm{TiO}_{2}$ to anaerobic microbes varied based on the biological processes. 
Recently, extensive research has been performed to understand the toxicity of fullerene $\left(C_{60}\right)$ ENMs to

497 diverse organisms. Tong et al. (2007) examined the toxic effects of $\mathrm{C}_{60}$ ENMs on the diversity of 498 microorganisms in both aqueous and soil systems. These results showed that $\mathrm{C}_{60}$ in an aqueous suspension does have adverse effects on bacterial cultures, while little impact was observed on the soil microbial community. In addition, Johansen et al. (2008) also reported that $\mathrm{C}_{60}$ caused only a small change of microbial community structure in soil. Lyon et al. (2005) suggested that the toxicity of $\mathrm{C}_{60}$ tended to associate more with the Gram-negative E. Coli, which is mainly attributed to the surface properties of the bacterial cell membrane. Thus, the toxicity of $\mathrm{C}_{60}$ to the specific group of microbes varied, and depended on environmental conditions. However, more research is needed to illustrate the mechanism of toxicity.

Bolyard et al. (2013) exposed coated nano-Ag, $-\mathrm{TiO}_{2}$ and $-\mathrm{ZnO}$ to old and middle aged MSW leachates and investigated their fate and effect on biological landfill processes. This experimental work highlighted that metal association and ENM attachment onto dissolved organic matter are important transformation processes regarding ENM mobility and potential for reduced toxicity. By applying ENM concentrations in the wide range of $0.1-100 \mathrm{mg} \mathrm{L}^{-1}$, there were no significant influences on the landfill's biological activity, represented as five-day biochemical oxygen demand and biochemical methane potential (Bolyard et al. 2013). Low concentrations of aqueous $\mathrm{Ag}, \mathrm{Ti}$, and $\mathrm{Zn}$ supported the lack of inhibition observed. Chemical speciation modelling did suggest that leachate components were associated with the aqueous metals. However, a similar study using nano-Ag, spiked to MSW materials at a concentration of $10 \mathrm{mg} \mathrm{kg}^{-1}$, showed that ENMs inhibited methanogenesis, probably attributed to the long-term and retarded release of their ionic constituents (Yang et al. 2013). Thus, considering the complexity of landfill leachate, the components could significantly influence the toxicity of ENMs either favourably or unfavourably.

\section{$5 \quad$ Recycling of ENM-containing wastes}

The actual amounts of recycled and recovered materials vary significantly from country to country and depend on local regulations as well as on the available technology. In many regions recycling and recovery efficiencies have been increasing because of proposed "zero waste" or "circular economy" strategies. Recycling options for wastes depend on the waste collection system, the type of collected waste, and 522 economics. In general, ENM-containing wastes can be chemically, biologically, thermally, or physically treated for recycling, influencing the fate of ENMs. 


\subsection{Potential ENM emissions}

525 During mechanical waste recycling processes, such as sieving, shredding, milling, grinding, or sorting, 526 ENMs may be released from the product's matrix and, consequently, may lead to workers' exposure and subsequently result in adverse environmental effects (OECD 2015; Struwe and Schindler 2012). The

528 Organisation for Economic Co-operation and Development (OECD) suggest that mechanical recycling 529 processes may result in the release of nano- $\mathrm{SiO}_{2},-\mathrm{TiO}_{2}$ and/or $\mathrm{CNTs}$ from polyethylene terephthalate (PET) bottles during shredding and regranulation processes (OECD 2015). Theoretical studies and reviews have highlighted that such nanoemissions during recycling operations may pose environmental hazards associated with occupational exposure and ENM release (e.g., Caballero-Guzman et al. 2015; Ding et al. 2017; Froggett et al. 2014; Mackevica and Foss Hansen 2016; Nowack et al. 2012; Part et al. 2016a; Wohlleben et al. 2014). Inhalation of ultra-fine particles (airborne nanoemissions) or dermal contact with solid/liquid residues after recycling operations illustrate potential environmental health risks that are currently very difficult to predict. To date, there is no clear evidence of ENM release leading to worker's exposure, as either no ENM-related monitoring programs have been conducted in existing waste recycling plants or no occupational health and safety reports have been provided for the public. A summary of potential ENM exposure and emission scenarios for recycling operations have been reported by the Organisation for Economic Co-operation and Development (OECD 2015).

A greater number of studies are needed to investigate the fate of ENMs during waste recycling operations. However, some recent laboratory-scale studies were conducted that aimed at quantifying 543 airborne emissions during production and recycling of CNT-containing composites (Bello et al. 2009; Bello 544 et al. 2010; Boonruksa et al. 2016a; Boonruksa et al. 2016b). Boonruksa et al. (2016a) conducted real-time aerosol measurements to determine the total particle number concentrations at the source of manufacturing 546 and during recycling processes (e.g., loading, melting, molding, and grinding). The highest reported 547 exposure to airborne ENMs were measured during the molding and grinding processes, however, no 548 significant differences in emitted quantities were observed between polypropylene containers with and 549 without CNTs. In this study, no free CNTs and only CNT-containing and matrix-embedded debris were 550 detected, which were comprised of respirable fibers. This fact is also in accordance to similar experimental 551 work on CNT-containing epoxy resins or polycarbonate composites (Bello et al. 2009; Bello et al. 2010; 
Boonruksa et al. 2016b). In particular, grinding processes lead to a release of diverse particles showing

553 diverse morphologies, at which predominantly agglomerates in both nano- and microscale were observed

554 (Boonruksa et al. 2016a; Boonruksa et al. 2016b). In this study it was stated that the number of times in

555 which a product was recycled had no significant impact regarding the quantity of nanoemissions. On the

556 contrary, the release of free CNTs from polymer composites caused by mechanical processes, such as

557 abrasion, brushing and/or wet sawing were observed by Methner et al. (2007), Golanski et al. (2012), and

558 Schlagenhauf et al. $(2012 ; 2014)$.

559 In summary, the type of stress, such as grinding, sieving or milling, and the way of embedding ENMs in 560 a product matrix are key factors influencing unintentional ENM release. Recycling processes may lead to 561 workers' exposure through inhalation of or dermal contact with nanoemissions. As monitored, mechanical 562 stress can lead to the release of respirable fractions and airborne emissions, exhibiting nano- as well as 563 microscale agglomerates or even free nanomaterials. Therefore, it is very important that worker exposure in 564 recycling plants is minimised by using protective measures (e.g., encapsulated systems, filters, protective 565 masks etc.). Moreover, future studies focussing on nanoemissions caused by recycling processes should 566 conduct in-depth ENM characterisation (towards chemical species, size, shape and element composition) 567 as well as consider toxicological aspects on the respirable fractions.

\section{$568 \quad 5.2 \quad$ Influence of ENMs on recycling processes and on quality of recovered materials}

ENMs may have an influence on the quality of recyclables, potentially leading to a decrease in its quality (e.g., mechanical properties) or may cross contaminate (where one hazardous chemical theoretically 571 transfers from one product to another one). Because there is a lack of studies focussing on ENM transport 572 and fate during waste recycling, these hypotheses cannot adequately be confirmed. Nevertheless, there are 573 indications that recycled ENM-containing polyethylene terephthalate packaging materials exhibit a reduced 574 product quality with regard to mechanical properties and colour (Sánchez et al. 2014). On the contrary, 575 recycling of polyethylene or polypropylene packaging materials, which contain nanoscale fillers and 576 additives (nanoclay, nano- $\mathrm{CaCO}_{3},-\mathrm{Ag}$ and $-\mathrm{ZnO}$ ), exhibited similar product quality towards durability 577 compared to their "ENM-free" counterparts (Sánchez et al. 2014). The authors pointed out that the product 578 quality of recycled plastics depends on its specific food applications (e.g.,ENM-containing food wrappings 579 are likely to be downcycled and not used again as packing materials). Zhang et al. (2016) experimentally 
investigated the fate of nano-ZnO during paper recycling and report that up to $91 \%$ of nano-ZnO ended up in 581 solid residues, which were sorted out and thus not reused for paper recycling, although nano-ZnO did not show a significant impact on the recovered fiber quality. In general, additional research on the influence of ENMs during recycling processes is needed, as there is an increasing amount of ENM-containing products at the market that can be recycled. nanotechnology-enabled recycling strategies. For example, a method was developed to selectively recover Au from ENM-containing wastes, at which additional LCA studies indicated that such recycling strategies can significantly reduce environmental impacts during gold manufacturing (Pati et al. 2016). Other case studies showed that waste streams can be used as a source for nanoscale raw materials, as exemplified on bio or plastic wastes, which were converted into carbonaceous ENMs (Suryawanshi et al. 2014; Zhuo and Levendis 2014). Another positive example is the use of nanoscale flame retardants, such as magnesium hydroxide, aluminium trihydrate, or calcium carbonate (nano- $\mathrm{Mg}(\mathrm{OH})_{2},-\mathrm{Al}(\mathrm{OH})_{3}$ or $-\mathrm{CaCO}_{3}$ ), which have a great potential for being applied to diverse plastics in order to substitute halogenated flame retardants 594 (Xanthos 2010). Consequently, cross-contamination by toxic brominated or chlorinated flame-retardants from post- to pre-consumer plastics (via recycling) may be reduced by the use of ENM-containing and less toxic non-halogenated plastics.

\section{Incineration of ENM-containing wastes}

Waste incineration is a common technology for waste treatment. Wastes are oxidised at high operating temperatures of $850{ }^{\circ} \mathrm{C}$ to $1100{ }^{\circ} \mathrm{C}$, leading to the elimination of pollutants or their accumulation in solid residues after incineration and may be attractive for ENM-containing waste disposal. During the last decade, several studies have been conducted to investigate ENM release and fate during waste incineration. Even large-scale experiments in Waste-to-Energy (WtE) plants have been carried out in order to study the 603 behaviour of nano- $\mathrm{TiO}_{2}$, nano- $-\mathrm{CeO}_{2}$, or nano- $\mathrm{BaSO}_{4}$ during combustion (Baran and Quicker 2016; Börner et al. 2016; Lang et al. 2015; Walser et al. 2012). In the following sections, both large and small-scale 605 experimental studies are discussed in more detail in order to review the state of knowledge associated with the incineration of ENM-containing wastes. 


\section{8 studies}

nucleation of heavy metal vapour after incineration with subsequent growth of fly ash particles through coagulation and condensation of other vaporized substances (nanoparticulate matter) and/or the direct release of ENMs from nanocomposites and ENM-containing products (Kumar et al. 2013).

A theoretical study by Mueller et al. (2012) and Mueller et al. (2013) aimed at modelling ENM flows through technical compartments, such as waste incinerators. The authors reported that two basic factors determined ENM behaviour during combustion:

(1) ENMs were either loosely or tightly bonded to another material; when ENMs were not tightly bonded,

point: $2900{ }^{\circ} \mathrm{C}$ ) remains morphologically unchanged, since this temperature is not reached during incineration. Only a small fraction of nano-Ag will evaporate, with the majority of this ENM remaining in the solid residues. The fate of ENMs during incineration is also strongly dependent on redox-conditions in the combustion zone. Considering the fate of nano- $\mathrm{ZnO}$ during incineration, when under reducing conditions, elemental $\mathrm{Zn}$ starts to evaporate at a temperature of $905^{\circ} \mathrm{C}$ (at $1150{ }^{\circ} \mathrm{C}$ to $90 \%$ ). Conversely, $\mathrm{ZnO}$ under oxidizing conditions is retained in a solid state at temperatures up to $1500^{\circ} \mathrm{C}$ (Mueller et al. 2013; Mueller et 

roughly $850-1100{ }^{\circ} \mathrm{C}$.

638 affect all of the basic properties of a material (Yokoyama 2012). Buffat and Borel (1976) showed that the 639 melting point of gold aggregates reduces with decreasing particle size. Gold particles having a diameter of 4 $640 \mathrm{~nm}$ start to melt at a temperature of approximately $400^{\circ} \mathrm{C}$ lower than the melting point of bulk gold $\left(1064^{\circ} \mathrm{C}\right)$ 641 (Buffat and Borel 1976). This phenomenon is known as the melting point depression and occurs (with few 642 exceptions) for almost all free ENMs. Due to the increased surface to volume ratio, surface atoms of an ENM 643 have a reduced cohesive energy, which is proportionally related to the thermal energy required to change 644 their state from solid to liquid. However, for some ENMs embedded in other host materials, an opposite 645 effect can be observed which is also known as superheating phenomenon. In this case, the melting point is 646 higher than for their bulk counterparts. Enhancement of the melting point can be influenced by interface epitaxy between ENMs and the embedding substance. The vibrational motion of the surface atoms is then 648 suppressed, leading to a delay of the melting process, but once the crystal bonds are broken, melting starts 649 (Nanda 2009).

650 Lang et al. (2015) suggested three hypotheses to explain what may happen with ENMs when they are 651 directly sprayed into a flame: (1) ENMs can be reduced to the single primary particles, either by 652 de-agglomeration or by sublimation and nucleation, (2) larger agglomerates are formed by coagulation, and 653 (3) larger aggregates are formed by sintering. Experiments conducted in a propane flame showed that the 654 thermal stability of nano- $\mathrm{CeO}_{2}$ agglomerates was influenced by various factors, including flame temperature 655 and retention time. The influence of the thermal energy on the ENMs causes the decrease of their modal 656 diameter (i.e., they became smaller) and the increase of their total number concentration (i.e., more $\mathrm{CeO}_{2}$ 657 particles were detected), which suggests that the particles emitted after combustion preserve neither their 658 primary form nor size. In addition, with increasing temperature, a growth of the total number concentration of 659 the newly formed ENMs was observed, which was attributed to either an intensive evaporation or 660 sublimation of the nano- $\mathrm{CeO}_{2}$ particles and a recondensation in cooler zones of the flame (Lang et al. 2015). 661 This observation confirms the findings concerning the reduction of the phase transition temperatures for free 
ENMs. It is noted that the used nano- $\mathrm{CeO}_{2}$ was exposed to experimental temperatures of $1450-1750{ }^{\circ} \mathrm{C}$, 663 whereas bulk ceria has a melting point of more than $2000^{\circ} \mathrm{C}$.

Experimental studies conducted by Vejerano et al. (2013) and Vejerano et al. (2014) focused on the characterisation of dust samples collected after the combustion of ENM-containing waste fractions in a laboratory-scale system. In addition, the morphological changes of the ENMs and their distribution between bottom and fly ash were determined. The ENMs used (nano- $\mathrm{TiO}_{2},-\mathrm{NiO},-\mathrm{CeO}_{2},-\mathrm{Ag},-\mathrm{Fe}_{2} \mathrm{O}_{3}, \mathrm{C}_{60}$, and quantum dots) were distributed in suspended form on paper and plastic wastes and subsequently incinerated at $850{ }^{\circ} \mathrm{C}$ (Vejerano et al. 2014). Results from this study indicated that the majority of ENMs were found in the solid combustion residues, with the largest amounts detected in the bottom ash and very small amounts in the fly ash. The only exception to this observation were the $\mathrm{C}_{60}$ fullerenes, which were released mostly unchanged with the dust particles, whereas according to theoretical assumptions isolated

$673 \mathrm{C}_{60}$ should be completely oxidized at approximately $500^{\circ} \mathrm{C}$. The authors noted that they could not close the mass balance for all of the investigated materials (losses in range of 10-25\%), mostly due to thermophoretic losses and due to non-detected, released volatile metal compounds. In general, it was found that the ENMs in the bottom ash remained morphologically unchanged and the primary particles retained their original size. Some nano- $-\mathrm{TiO}_{2},-\mathrm{CeO}_{2}$ and $-\mathrm{Fe}_{2} \mathrm{O}_{3}$ formed large aggregates encapsulated by other ash components. Nano-Ag and - NiO and CdSe quantum dots did not form aggregates but were to some extent larger than the 679 initial particles, which served as evidence for melting and reforming processes occurring. Furthermore, some metal chlorides and sulfides were detected in the solid residues, suggesting that ENMs may undergo transformation processes and chemical reactions with other waste components. The measurements in the exhaust gas indicated that the number concentration of dust particles was admittedly higher while adding ENMs to waste samples, but the differences were not significant. These results also indicated that the combustion process itself was influenced by some ENMs. For example, nanoscale metal oxides decreased 685 the emissions of polycyclic aromatic hydrocarbons, presumably because of their intrinsic catalytic 686 properties. On the contrary, nano-Ag enhanced the overall emissions. In summary, the authors emphasized 687 that the growth of particles during combustion depends strongly on nucleation, aggregation, and 688 agglomeration processes and heterogeneous reactions with other gaseous species. Although the 689 morphology of the investigated materials were not drastically modified, some structural changes, like 
transition from anatase to rutile for nano- $\mathrm{TiO}_{2}$ were also observed (Vejerano et al. 2013; Vejerano et al. 691 2014).

692 The foci of previously cited works were on free ENMs tested in their original and dispersed form. These studies give a general understanding of primary mechanisms influencing the fate and behaviour of ENMs during incineration processes. ENM-containing composites (nanocomposites) were also investigated in order to simulate more realistic conditions during thermochemical treatment (Bouillard et al. 2013; Ounoughene et al. 2015). The study by Bouillard et al. (2013) focused on acrylonitrile butadiene styrene (ABS) injection-molded nanocomposites filled with $3 \% \mathrm{w} / \mathrm{w}$ of multiwalled carbon nanotubes (MWCNTs). MWCNT fibers per se were produced by catalytic chemical vapour deposition and consisted of $90 \%$ of carbon and $10 \%$ of trace metallic catalysts. The used ABS/MWCNT-composites were incinerated at the laboratory scale over a temperature range of $460-600{ }^{\circ} \mathrm{C}$ at different oxygen levels. The measurement of the ENM fractions sampled in the gas phase revealed nanoemissions that originated from combustion of ABS/MWCNT comprising single as well as bundled CNT fibers in all investigated cases. Finally, the detected CNTs had a similar shape compared to their pristine equivalents (with a size of $12 \mathrm{~nm}$ in diameter and $600 \mathrm{~nm}$ in length including catalysts traces attached to the end of fibers). Authors of the study demonstrated that not all MWCNTs were combustible and thus can be dispersed in the gas phase although they are defined per se as combustible materials. Such behaviour of carbonaceous ENMs corresponds with the findings of Vejerano et al. (2014).

Ounoughene et al. (2015) carried out incineration tests on nanoclay-based nanocomposites (nylon-6 incorporating halloysite nanotubes, abbreviated as PA6/HNTs) using a laboratory-scale tubular furnace.

710 The simulated WtE-plants parameters involved: division into combustion and post-combustion zones, 711 temperature of $850^{\circ} \mathrm{C}$, high oxygen/fuel contact, and at least $2 \mathrm{~s}$ of residence time for combustion gas. This 712 study investigated the influence of HNTs on combustion mechanisms by characterizing the combustion 713 residues and aerosols. The nanocomposite samples were prepared, analogously to Bouillard et al. (2013), 714 by injection molding. Based on the on-line measurements for particle number and gas concentration as well 715 as imaging methods, the authors suggested a two-step mechanism of the thermal decomposition of 716 PA6/HNTs samples. After sample ignition, a high release of particles and gas components were observed. 717 By complementary thermogravimetric analyses, results indicated that dehydration of HNTs, thermal ablation 
718 of PA6, and decohesion of the composite components occurred. Increased concentration of HNTs on the

719 probe surface resulted in the formation of protective layers, which delayed the complete oxidation of the 720 nanocomposite. Ounoughene et al. (2015) assumed that nanoclays are promoters for charring processes, 721 at which an additional protective layer leads to a limited mass and thermal transfer. HNT-reinforced char 722 was decomposed firstly by cracking and secondly by oxidizing. After this, the sample was completely 723 oxidised and a mineral-consisting combustion residue, derived from the initial HNTs, was collected. 724 Furthermore, the presence of HNTs caused, compared to pristine ENM-free PA6, higher carbon monoxide 725 as well as particle emissions (due to the previously described two-step mechanism). However, the sampled 726 aerosols contained mostly soot particles (from polymer combustion) and minor aggregates of distorted 727 HNTs (prismatic instead of tubular), which were found in submicron dust fractions. Ounoughene et al. (2015) 728 noted that the aggregated state of ENMs can be explained by sintering processes, at which distortion of 729 HNTs resulted to thermal transformation into other mineral structures. Moreover, Froggett et al. (2014) also 730 reviewed studies about ENMs, such as $\mathrm{CNTs}$, nanoscale graphite, nanoclays or nano- $\mathrm{TiO}_{2}$, having 731 fire-retardant properties. The authors concluded that enhanced thermochemical stability of some 732 nanocomposites should be considered as another important factor for determining the fate and behaviour of 733 ENMs during incineration.

734 As pointed out in the previously described studies, despite low transfer factors of primary ENMs to the 735 flue gas (except for carbon nanomaterials), secondary re-formation of ENMs cannot be excluded. Such 736 nanoemissions can be generated during combustion as a result of either physical (e.g., 737 volatilization/sublimation and further recombination) or chemical transformation processes (e.g., soot 738 formation) (Kumar et al. 2013). In order to investigate the fate and transport of airborne nanoemissions via 739 the flue gas stream, Forster et al. (2016) provided a population balance model and showed that the 740 underlying mechanism describing ENM separation consisted of two processes: (1) diffusion scavenging and 741 (2) self-aggregation. ENMs formed after incineration are first cooled down with fly ash particles at different 742 stages of the gas cleaning system. During this process, they undergo Brownian collisions, which results in 743 an adherence to coarse fly ash particles (scavenging of ENMs) and self-aggregation. Scavenging is 744 favourable for ENM removal as the created fly ash particles are larger, contributing to a continuous growth of 745 dust cake and thereby increasing the filtration efficiency of fibrous filter mediums. Effectiveness of the 
scavenging can be, however, reduced due to the dominant self-aggregation (by increased particle size).

747 This may be the case for higher concentrations of ENMs. To avoid self-aggregation, the injection of additives

748 used during flue-gas cleaning was proposed ("dilution" of ENM concentration). Furthermore, Forster et al.

749 (2016) assumed that scavenging is only dependent on the particle size, not the chemical composition.

750 Under consideration of realistic conditions for waste incineration plants, these modelling results indicated

751 that up to $80 \%$ of the ENMs can be scavenged in flue gas duct. The determined filtration parameters (i.e.,

752 pressure drop etc.), which are required for sufficient filtering of ENMs, correspond with typical operational

753 conditions for existing fabric filters in conventional WtE plants (Forster et al. 2016). In conclusion, removal

754 efficiencies for similar filter technologies for ENM-containing wastes are comparably high as those for

755 wastes containing no ENMs (Baran and Quicker 2016; Forster et al. 2016).

\subsection{ENM fate in WtE plants at large scale}

As a continuation of the laboratory-scale experiments, Lang et al. (2015) investigated the behaviour of nano- $\mathrm{CeO}_{2}$ in a pilot incineration plant for special wastes fueled by natural gas and coal dust. The plant was equipped with a rotary kiln incinerator and an emission control unit fulfilling the requirements of the best available techniques for waste incineration. During the tests, a nano- $\mathrm{CeO}_{2}$ suspension was sprayed directly into the furnace. Aerosol samples were subsequently collected in the post combustion chamber, behind the boiler, and at the stack and cerium mass balances were calculated. After subtracting the background concentration for both fuels, a recovery of only $10 \%$ of applied cerium mass was recovered. Similarly to Vejerano et al. (2014), the authors attributed this effect to thermophoresis occurring on the combustion chamber's lining. According to these results, the installed flue gas cleaning system removed $>99 \%$ of the ceria particles transferred to the flue gas duct. The peaks in particle size distribution of detected airborne Ce-particles were shifted to the submicron (gas co-combustion) and micron sizes (coal dust co-combustion), which indicated a tendency for the nano- $\mathrm{CeO}_{2}$ to adhere to larger dust particles by higher dust concentrations (Lang et al. 2015). This observation is similar to the findings of Forster et al. (2016). extensive study conducted by Walser et al. (2012). This work represents the first study focused on

772 intentionally introducing ENMs in a MSW incineration plant during normal operation. In the plant, two "worst 773 case scenarios" for disposal of nano-ceria were investigated. In the first case, nano- $\mathrm{CeO}_{2}$ was sprayed in 
774 the form of an aqueous suspension onto the waste, just before it entered the combustion zone. Thus, the 775 input of large quantities of free ENMs during combustion was simulated. In the second experiment, the 776 suspension was sprayed directly into the combustion chamber through nozzles used for ammonia addition 777 and was conducted to simulate high ENM transfer into the flue gas. The main objective of this work was to 778 validate the functionality of the flue gas treatment. Aerosol sampling from the flue gas took place after the 779 electrostatic precipitator and after the scrubber. In addition, fly ash samples from the boiler and the 780 electrostatic precipitator as well as the solid combustion residues from the grate furnace were collected. 781 Mass distribution for cerium as a trace element was calculated. Results from this work indicate that $39 \%$ 782 (during the first experiment) and $34 \%$ (second experiment) of the introduced nano- $\mathrm{CeO}_{2}$ was recovered. 783 Due to the high complexity of the incineration plant, already subtracted background concentration, and low concentrations of added ENMs, the authors considered the recovery to be the high. The majority of the 785 cerium $81 \%$ to $53 \%$ was detected in the slag and $19 \%$ to $45 \%$ ended up in the fly ash (in case 1 and 2 , respectively). In both cases over $99 \%$ of the cerium dioxide, which was dispersed in the gas phase, was removed from the flue gas by the electrostatic precipitator and wet scrubber. A value of $0.0001 \%$ was determined as a transfer coefficient of nano- $\mathrm{CeO}_{2}$ to the discharged purified gas. Therefore it can be concluded that the utilized flue gas cleaning system is an effective combination for ENM removal from the exhaust gases after waste incineration. Imagery of slag and aerosol samples revealed no morphological transformations of nano- $\mathrm{CeO}_{2}$ after thermal treatment. Remaining nano- $\mathrm{CeO}_{2}$ left in the furnace was physico-chemically unchanged as crystalline particles in loose agglomerates on the surface of the residue matrices (Walser et al. 2012).

In order to extend the knowledge and validate the results for other inorganic ENMs, Börner et al. (2016) and Baran and Quicker (2016) conducted similar experimental measurements in commercially operating 796 thermal waste treatment facilities. Börner et al. (2016) examined how nano- $\mathrm{TiO}_{2}$ transfers from combustion 797 to the filtering system. ENMs in suspended form were injected into the fuel in the charging hopper (waste 798 incineration plant) and in front of the solid pumps, transporting the sludge into the combustion chamber 799 (sewage sludge incineration plant). This spiking method corresponds with "case 1" applied by Walser et al. 800 (2012). The results of the measurements in the MSW incineration plant exhibited a very high and strongly 801 fluctuating background concentration of titanium in all samples, which caused difficulties in quantifying the 
effects resulting from the addition of nano- $\mathrm{TiO}_{2}$ and had an influence on the calculated recovery (between 71

803 and 124\%). Note that this measuring inaccuracy can result in values above $100 \%$. Nevertheless, increases

804 in the titanium concentration were high enough to complete the mass balance, which showed that $91-96 \%$

805 of the titanium (based on the total amount of recovered titanium) remained in the bottom ash. The results

806 from the sewage sludge incineration plant showed similar tendencies in the behaviour of nano- $\mathrm{TiO}_{2}$,

807 although the applied incineration technology could be associated with higher dust loads in the untreated flue

808 gas due to the fluidisation of the combustion bed. Despite the huge differences in recoveries ranging

809 between 16 and 100\%, the majority of titanium (90-94\%) accumulated in the solid combustion residues.

810 The dust measurements along the exhaust gas path indicated no significant differences in the titanium

811 concentration compared to the blank test in both plants. This was similar to the reduction of dust loads,

812 which can be attributed to the high separation efficiency of the tested flue gas cleaning systems (Börner et

813 al. 2016).

814 Comparable conclusions by Walser et al. (2012) and Börner et al. (2016) can be drawn when getting 815 acquainted with findings of Baran and Quicker (2016). The study on emission behaviour of nano-BaSO ${ }_{4}$ in a 816 MSW incineration plant (roller grate furnace, boiler, dry exhaust gas purification unit, fabric filter and 817 selective catalytic reduction) revealed that almost $87 \%$ of recovered ENMs were found in the bottom ash, 818 8.5\% in boiler ash, and $4.5 \%$ in residue from fabric filter (Quicker and Stockschläder 2017). The calculated 819 recovery amounted to $68 \%$; the separation efficiency of the fabric filter for the barium particles was more 820 than $99 \%$. The authors revealed that tested ENMs tended to sinter in accordingly lower temperatures than bulk $\mathrm{BaSO}_{4}$ (shrinkage starting temperature is lower around $100{ }^{\circ} \mathrm{C}$ ) and exhibited a stronger tendency to 822 adhere to fly ash particles after combustion (Baran and Quicker 2016). In conclusion, incineration of MSW 823 and sewage sludge can concentrate metals in the incineration slags (bottom ashes) or fly ashes deposited in 824 landfills (e.g., in "ash" or residual waste landfills). Depending on the incineration method or material (e.g., 825 MSW, sewage sludge, etc.), the mineralogical phase of the solid residues, their associated metal content 826 and the morphology of the inclusion can all be highly variable. The residues from waste incineration 827 potentially comprise of highly concentrated ENMs and will either be landfilled or used for recycling materials 828 (e.g., construction materials). 
830 Municipal and non-hazardous waste landfills are likely to serve as the final environmental sink for many 831 ENM-containing wastes (e.g., consumer products, end-of-life plastics, or slags from incineration), as 832 predicted by several material flow models (Caballero-Guzman et al. 2015; Gottschalk et al. 2010; 833 Heggelund et al. 2016; Hincapié et al. 2015; Keller and Lazareva 2014; Mueller et al. 2013; Sun et al. 2017; 834 Suzuki et al. 2018b). For example, Keller et al. (2014) estimated that up to 190,000 tonnes of the ten major 835 and global ENM flows (i.e., nano- $\mathrm{Ag},-\mathrm{Al}_{2} \mathrm{O}_{3},-\mathrm{CeO}_{2},-\mathrm{Cu},-\mathrm{Fe},-\mathrm{SiO}_{2},-\mathrm{TiO}_{2}$, and $-\mathrm{ZnO}, \mathrm{CNTs}$, and nanoclays) 836 will ultimately reside in landfills. The following sections describe what is currently known about the behaviour 837 of ENMs in landfills.

\subsection{Potential nanoemissions from landfill sites}

Figure 2 summarises the potential ENM fate at landfill sites. ENMs may be directly landfilled as production wastes or embedded within ENM-containing products (i.e., pre- and post-consumer).

Pre-treatment of these wastes using techniques such as aerobic degradation or incineration may lead to

842 ENM accumulation in solid residues, which, depending on specific waste management regulations, will likely 843 be landfilled. Once these wastes are landfilled, mechanical or chemical processes may lead to ENM release 844 from end-of-life products and/or ENM transformations (e.g., natural weathering, alteration/degradation 845 processes, mechanical stress) (Lozano and Berge 2012; Musee 2011b; Part et al. 2016b; Reinhart et al. 846 2010). ENMs may ultimately be released from the landfill through liquid and gas emissions or by wind 847 erosion. The type and operation of landfills (which is country-specific) and leachate characteristics, such as $848 \mathrm{pH}$, ionic strength, total or dissolved organic carbon (TOC or DOC, respectively) content, are likely to 849 influence ENM mobility and ultimately their fate.

850 No studies have been published that focus on the in-situ monitoring of airborne nanoemissions and 851 ultrafine particles $\left(\mathrm{PM}_{0.1}\right)$ stemming from landfill sites. However, at the laboratory scale, Buha et al. (2014) 852 simulated a dispersion process on incineration bottom and fly ashes that is comparable to possible wind 853 erosion on landfills and concluded that such processes can only re-break loosely bound agglomerates and 854 not tightly bound aggregates into individual ENMs. It should be noted that agglomerates consists of weakly 855 bound particles, whereas aggregates are comprised of strongly bound or fused particles (EC 2011). 
ENM release from landfill sites is more likely to be caused by hydro/geochemical processes. In general, release of ENMs in saturated solid matrices can be caused by weathering and degradation processes, depending on the diffusion coefficient of an ENM as well as on the ionic strength, pH value, valence of ion, and redox potential prevailing in the matrix (McCarthy and Zachara 1989; Wagner et al. 2014). In this context it is important to note that ENM transfer from the solid phase to landfill leachate highly depends on environmental conditions and surface chemistry (i.e., coated or uncoated) of the ENM (Reinhart et al. 2010). Reinhart et al. (2010) suggest that ENMs that are dispersed within liquids or gels may be more easily transferred to the leachate stream than ENMs that are tightly embedded in a solid product matrix (e.g., nanoscale additives in plastics). Under harsh environmental conditions (e.g., high alkaline pH in leachates from residual / ash landfills or at acidic $\mathrm{pH}$ in young MSW leachates) ENMs are likely to also be transferred to the leachate stream, as such conditions can lead to enhanced decomposition and alteration processes of the parent product matrix.

In-depth investigations on field-scale landfills have confirmed the abundance of nanoparticulate fractions in leachates (Hennebert et al. 2013; Jensen and Christensen 1999; Kaegi et al. 2017; Matura et al. 2012; Mehrabi et al. 2017; Mitrano et al. 2017), although it should be noted that the origin of these nanoemissions may be from natural sources or from ENMs. Alteration and weathering processes could cause unwanted ENM release that may consequently pose a threat towards groundwater contamination and may lead to unknown adverse impacts on the environment. However, a recent laboratory study evaluating

874 the diffusion potential of MWCNTs through a simulated high-density polyethylene (HDPE) geomembrane 875 indicate that their permeation was relatively low, with diffusion coefficient estimated to be less than $5.1 \times 10^{-15}$ $876 \mathrm{~m}^{2} / \mathrm{s}$ (Saheli et al. 2017). In addition to these laboratory-scale tests, Saheli et al. (2017) modelled different 877 scenarios with HDPE geomembranes and geosynthetic clay liners and concluded that such technical barriers are effective for MWCNTs. However, it should be noted that worldwide there are many open landfills 879 and dumps without any engineered barrier. In these landfills, ENM release to the environment (e.g., via the 880 leachate stream) may occur. Additionally, in landfills containing effective bottom-liner systems, ENMs may 881 be released to the environment during the leachate treatment process. Thus, it is critical to understand the 882 fate and transport of ENMs in landfills. It is likely that the physical, chemical, and biological transformation 883 processes (e.g., agglomeration/aggregation, particle dissolution, oxidation, sulfidation, or biodegradation) 
occurring within landfills influence ENM mobility and environmental fate (Lowry et al. 2012b; Mitrano et al.

885 2015; Part et al. 2015; Peijnenburg et al. 2015).

\subsection{Measured liquid nanoemissions from landfills}

Measurements of ENMs in liquids from exiting landfills is currently very challenging because it is difficult to differentiate between ENMs and their naturally occurring or incidentally released counterparts in complicated matrices, such as landfill leachate (Part et al. 2015). In addition, because the processes associated with ENM fate and transport are not fully understood, predicting ENM transport is also challenging (Dale et al. 2015; Nowack et al. 2015; Peijnenburg et al. 2016). In recent studies conducted at the laboratory scale, heteroaggregation of ENMs with natural colloids and nanomaterials were reported to play a key role regarding ENM fate in the aquatic environment (Praetorius et al. 2012; Quik et al. 2012; Quik et al. 2014). Thus, important information can be gained from characterisation and fate of natural nanoscale and colloidal fractions found in landfill leachates. Several investigations (Gounaris et al. 1993; Hennebert et al. 2013; Jensen and Christensen 1999; Li et al. 2009; Øygard and Opedal 2007) have documented characteristics of colloidal matter typically found in landfill leachates. Colloidal suspensions in landfill leachate have been found to consist of sizes ranging from $1.3 \mathrm{~nm}-10 \mu \mathrm{m}$ and have been observed to remain stable (i.e., turbidity and size fractionation was constant) in suspension for over 24 hours (Gounaris et al. 1993). This high stability implies a high degree of mobility and persistence (Gounaris et al. 1993). These colloids generally contain an inorganic core (e.g., calcium, phosphate) surrounded by organic matter (Baumann et al. 2006; Gounaris et al. 1993; Jensen and Christensen 1999). Often heavy metals and other salts are complexed with the colloids (Baumann et al. 2006; Gounaris et al. 1993; Jensen and Christensen 904 1999).

A field study by Kaegi et al. (2017) showed that ENMs, such as nano- $\mathrm{TiO}_{2}$, can be release from landfills for construction and demolition wastes. The authors reported that the total elemental Ti content of 907 the leachate was around a few tens of $\mu \mathrm{g} / \mathrm{L}$ and was strongly correlated with total suspended solids. The 908 annual emission of $\mathrm{TiO}_{2}$ particles was estimated to be $0.5 \mathrm{~kg} / \mathrm{y}$, and nanoscale $\mathrm{TiO}_{2}$ particles to $0.5 \mathrm{~g} / \mathrm{y}$, with a predominance of spherically shaped $\mathrm{TiO}_{2}$ particles, indicating their man-made origin (i.e. from micro- and nanoscale white pigments). 
In landfills containing solid residues from incineration, a study on the mobility of released metallic ENMs

912 showed that $\mathrm{Zn}, \mathrm{Ag}$, and Cu were present in the low $\mu \mathrm{L} \mathrm{L}^{-1}$ range and associated with nanoparticulate matter

$913(1-100 \mathrm{~nm})$ and colloidal fractions $(0.1-0.45 \mu \mathrm{m})$ (Mitrano et al. 2017). ENMs consisting of $\mathrm{TiO}_{2}$ and $\mathrm{Zn}$, as

914 well as microscale Fe particles were also found in the leachates. Results from this study highlight that the

915 proportion of associated metals with colloids in different sizes is highly dependent on the type and age of the

916 landfill site. However, other studies focusing solely on the leaching behaviour of incineration residues found

917 that most metal-containing nano- and colloidal particles were by-products of the incineration process rather

918 than released ENMs retaining their original properties (e.g., Köster et al. 2007; Saffarzadeh et al. 2011).

\subsection{Influence of landfill leachate characteristics on ENM mobility}

In general, ENM transport and mobility in landfills depends on following factors: (1) how ENMs are embedded within the parent product, (2) ENM-related properties, and (3) landfill characteristics, including leachate composition and waste characteristics. In general, potential ENM release from products generally depends on whether ENMs are dispersed in bulk products, in coated surfaces, bound within products, or directly used in industrial processing (Yang and Westerhoff 2014). For example, $\mathrm{CeO}_{2}$ nanopowders are used as polishing agents that also needs to be disposed of at the end of their useful life. In the case of discarded ENM-containing products, ENM release may be driven by physical and/or chemical stressors (see also Section 3.2), in which ENM release is basically triggered by desorption, diffusion, dissolution, and/or matrix degradation (Duncan and Pillai 2015). Once ENMs are released into the environment, detachment/attachment of ENMs and heteroaggregation, such as the attachment of suspended natural organic matter (NOM) (onto the particle surface leads and consequently block their potential deposition sites), represent key processes influencing ENM transport and mobility (Peijnenburg et al. 2016). It should be noted that for environmental matrices, heteroaggregation is potentially more important than homoaggregation processes (e.g., NOM-ENM or ENM-ENM interactions, respectively) (Lowry et al. 2010), although studies at conditions relevant to those found in landfills have not been studied.

If ENMs are transferred to the leachate, the colloidal stability of ENMs will likely determine their mobility and environmental fate (Wagner et al. 2014). Key ENM properties that influence colloidal stability include 937 particle size, size distribution, shape, specific surface area, and surface properties (i.e., grafting density of organic ligands, surface charge, and functionality), where the latter material properties predominantly 
determines whether an ENM is hydrophilic or -phobic (Part et al. 2015). It should also be noted that

940 environmental conditions, such as $\mathrm{pH}$, ionic strength, electrolyte concentration, and NOM content 941 significantly influence ENM mobility and transport in (saturated) porous solid matrices, as experimentally 942 reported by several researchers (Akaighe et al. 2011; Clavier et al. 2016; Ghosh et al. 2008; Radniecki et al. 943 2011; Tejamaya et al. 2012; Yang et al. 2015; Zhou et al. 2013). Significant work in the field of ENMs has 944 been conducted evaluating the influence of these ENM and environmental conditions on ENM stability and 945 thus transport in liquid and solid matrices (e.g., Chen and Elimelech 2006; Hotze et al. 2010; Li et al. 2008; 946 Louie et al. 2016; Petosa et al. 2010; Phenrat et al. 2010; Saleh et al. 2010).

947 When considering ENM stability/mobility in landfills, it is important to consider that landfill 948 characteristics are distinct from the type of landfill and can significantly change over time. For example, the 949 950 951 952 leachates is predominantly organic acids (e.g., acetic, propionic, butyric), while leachates from older landfills contain more complex organics, such as humic and fulvic acids. Lozano and Berge (2012) highlight how changes in the type of organic can influence ENM stability and thus transport. In transport experiments simulating young leachates (organic source was acetic acid), significant CNT aggregation and little CNT transport was observed. However, in leachates representing older landfill conditions (organic source was humic acid), significant CNT transport was observed, even in the presence of high concentrations of electrolytes. A significant body of literature describing the influence of organic type and electrolyte 961 concentration on ENM stability is available (e.g.,Chen and Elimelech 2006; Li et al. 2008; Louie et al. 2016; Phenrat et al. 2010; Saleh et al. 2010).

963 Another important component associated with ENM fate and transport in solid waste environments is 964 transformation of the particle and/or particle coating during transport. Lowry et al. (2012a) and Levard et al. 965 (2012) reported on the possible ENM transformations with time. The particle coating may deteriorate over 966 time and, if the particle is metallic, dissolution of the metal may occur. Transformations associated with the 
released particles will ultimately influence their fate in landfills. Little work in leachate relevant conditions has 968 been conducted investigating these particle transformations.

To date, there are no in-situ studies published that aim at elucidating ENM transport and mobility through field-scale landfills. For simplification, some studies investigated ENM mobility by applying leaching or batch tests under laboratory conditions. A study by Sakallioglu et al. (2016) showed that the leaching behaviour of nano- $\mathrm{ZnO}$ in a MSW batch reactor was not significantly affected by the prevalent $\mathrm{pH}$ and ionic strength, where the majority (up to $\sim 93 \%$ ) of nano-ZnO were retained and adsorbed to the solid MSW matrix. Dulger et al. (2016) conducted batch tests under similar conditions and showed that the retention capacity of MSW was sufficient and far from saturation in order to retard nano- $\mathrm{TiO}_{2}$. In this context it needs to be mentioned that currently it is very challenging or almost impossible to distinctively differentiate, for example, man-made nano-ZnO from naturally occurring $\mathrm{Zn}$ species that occur in relatively high concentrations (up to $\sim 100 \mathrm{mg} \mathrm{L}^{-1}$ or higher). As a consequence, additional work is needed to draw specific conclusions about ENM transport and permeability in landfills bodies.

Part et al. (2016b) studied the potential mobility of sterically stabilized fluorescent nanocrystals (quantum dots or QDs), which were dispersed in real MSW landfill leachates and stored at different temperatures for over more than six months. Their laboratory-scale tests indicated that the $\mathrm{pH}$ did not significantly influence the colloidal stability of QDs, as the $\mathrm{pH}$ in mature MSW landfill leachates showed high $\mathrm{pH}$ buffer capacities due to abundant carbonates and therefore remained stable for the whole period under consideration. However, the authors concluded that QD colloidal stability and potential transformation processes in the MSW landfill leachate used was predominantly affected by the residence time, sample storage temperature, DOC, and electrolyte content. In addition, Part et al. (2016b) emphasised that the specific particle surface properties or capping agents, which are commonly used for steric stabilization (e.g., organic acids or surfactants), significantly influenced ENM mobility in MSW landfill leachates.

In general, the presence of NOM or DOC is of particular note as particle-particle interactions may lead to overcoating of ENMs and, consequently, to further steric stabilisation and enhanced ENM mobility (Lowry et al. 2012b). Bridging or adsorption of natural macromolecules, such as proteins, DNA, fulvic or humic acids 993 that can be found in landfill leachates significantly influences ENM transport and fate in the environment 994 (Louie et al. 2016). Results from a study evaluating ENM mobility through saturated simulated mixed MSW 
indicated that $\mathrm{DOC}$ and the ionic strength of the solution had a significant impact on the mobility of single 996 wall carbon nanotubes (SWNTs) through packed MSW columns (Lozano and Berge 2012). A 997 complementary study showed that SWNT mobility decreased with decreasing DOC content (Khan et al. 998 2013). These experimental studies highlight that the age of landfill leachates, in which $\mathrm{pH}$ or DOC content 999 can significantly change over time, as well as the change in waste composition significantly influences SWNT mobility.

1001

Another laboratory-scale study about ENM behaviour in MSW landfill leachates have investigated the 1002 influence of a trace organic compound on the colloidal stability of ENMs (Lee et al. 2015). By using the example of $17 ß$-estradiol, a steroid hormone which is routinely detected in municipal wastewater and landfill leachates from its use as a medication for hormone replacement therapy, in the concentration range from 0.1-3.0 mg/L, Lee et al. (2015) observed that this compound was quickly adsorbed onto nano- $\mathrm{TiO}_{2}$ which caused increases in nano- $\mathrm{TiO}_{2}$ aggregation, indicating its importance regarding contaminant transport as well as ENM mobility. However, the influence of such trace organic compounds and of humic acid was less 1008 pronounced at higher ionic strengths that may be more representative of real landfill leachate (Lee et al. 1009 2015).

\section{Conclusions, identification of knowledge gaps, and future research questions}

Literature associated with the fate of ENMs in waste fractions was reviewed and summarized. 1012 Literature associated with each step in the expected management and treatment of ENM-containing wastes 1013 exists (e.g., composition, composting, recycling, incineration and landfilling), suggesting this emerging issue 1014 of ENM fate is being actively explored. As illustrated in Figure 3, of the papers reviewed, 33\% focused on 1015 biological treatment, while $22 \%$ of the articles were related to the landfilling of these wastes. Incineration of 1016 ENM-containing wastes appears to be the least explored waste management process ( $11 \%$ of articles). The currently most explored waste stream is MSW, with food and commercial wastes representing the next two 1018 most explored waste streams (Figure 4). Within these waste streams, the fate of a variety of ENMs was 1019 investigated; the most explored ENMs were nano-Ag and nano- $\mathrm{TiO}_{2}$ (Figure 4).

Although databases containing ENM content in consumer products exist and continue to be updated, 
wastes exists. In addition, the release of ENMs from consumer products under conditions representative of those found in relevant waste management process has not been specifically studied, but is needed.

A somewhat limited number of laboratory-scale experiments evaluating the composting of MSW spiked with different ENMs have been conducted (Figure 3). Of the experiments conducted, the majority concluded that ENM presence does not influence waste degradation processes. However, other components of the composting process, such as microbial community structure, may be influenced. Alteration and biological degradation processes of ENMs per se could also be investigated in more detail (e.g., of CNTs, $\mathrm{C}_{60}$, or inorganic ENMs having organic surface coatings). The studies conducted provide an initial framework for understanding ENM fate during composting, but additional research investigating a greater range of ENM types, concentrations, and surface chemistries (e.g., pristine and with a variety of capping agents), solid organic composition, aeration rates, and moisture contents is needed. In addition, a greater number of experiments evaluating the impact of land application of ENM-containing composts are needed and is critical to predict future viability and success of composting processes.

Few studies have investigated the fate of ENMs during waste recycling, with the majority of studies focusing on ENM fate and/or recyclability at the laboratory-scale (Figure 3). The large number of recycling processes used complicate understanding the fate of ENMs during recycling. An important aspect of ENM recycling that required immediate exploration is the potential for worker exposure. ENMs may also influence on the quality of recyclables, potentially decreasing product quality. However, because of the lack of studies in which this has been explored, such hypotheses or conclusions cannot be confirmed.

Both small and large-scale studies evaluating the fate of ENMs during incineration have been conducted (Figure 3), with the majority of studies focusing on laboratory-scale studies. The results of the studies in WtE plants seem to partially confirm the theoretical assumptions derived from laboratory-scale experiments, but due to inhomogeneity of the wastes and complexity of chemical conditions during waste incineration results cannot be directly compared. In addition, conclusions from these studies are complicated by the lack of ability to discriminate between original (pristine) ENMs, combustion generated nano-objects, and those that occur naturally. Being able to overcome these challenges is an essential step forward in this research area. Despite these complexities, the conducted studies have shown in all likelihood that in most cases the inorganic ENMs end up in the bottom ash or slag after waste incineration. Depending 
on their specific properties (which strongly differ from bulk-materials), they can either retain their original

1051 form or be chemically and physically changed. Airborne nano-objects can be effectively separated by existing flue gas cleaning systems because of their strong tendency to agglomerate/aggregate. On the other hand, as proven only during laboratory-scale experiments, carbon nanomaterials can be transferred to a large extent to the gas phase despite their combustible nature. Since no large-scale experiments for carbon nanomaterials were reported thus far, investigation of their behaviour in WtE plants is still needed.

In terms of landfilling, no studies reported on the monitoring of nanoemissions from operating landfill sites (Figure 3). Many studies focused on understanding the influence of landfill leachates on ENM stability and mobility (Figure 3), while the release mechanisms and ENM transfer from solid wastes to the leachate stream remain rather unexplored and is still not fully understood. In order to assess the potential transport behaviour and mobility of ENMs in landfills it is crucial to consider material- and matrix-related properties, which can be significantly alter over time and vary with the type of landfill, as well as potential transformation processes of ENMs that likely occur. Incidental surface modification of ENMs due to the presence of leachate solutes as well as natural macromolecules and nano-objects can significantly affect ENM transport and fate in waste disposal systems (Lee et al. 2016). Future studies may focus on potential ENM transfer mechanisms from the solid phase to leachates, while developing ENM-specific analytical tools to quantify attachment and deposition processes, as also recommended by Mitrano et al. (2015) and Part et al. (2015). In addition, future studies need to overcome the challenge of differentiating between natural and engineered nanomaterials. In the future, complementary in-situ studies about airborne nanoemissions are also needed, as there is no knowledge about the actual contribution of these particles to air pollution.

There is a strong need to continue investigating the fate and transport of ENMs during each phase of ENM-containing waste management and treatment. As a result of this review of literature detailing the current knowledge surrounding the fate of ENMs in MSW streams, a series of knowledge gaps and specific 1073 research questions have been identified and are listed in Table 4. Answering these questions will provide 1074 the information necessary to develop appropriate management strategies for ENM-containing wastes, 1075 which can subsequently be used to shape regulations governing the definition and management of these 1076 wastes. It should also be noted that other complexities associated with analytical approaches to measuring 1077 and quantifying ENMs in waste streams and emissions from these waste processes (Figure 1) complicate 
1078

1079

1080

1081

1082

1083

1084

1085

1086

1087

1088

1089

1090

1091

1092

1093

1094

1095

1096

1097

1098

1099

1100

1101

1102

1103

1104

1105

1106

1107

1108

1109

1110

answering the research questions identified in Table 4. Being able to monitor future nanoemissions, novel and ENM-specific analytical tools need to be developed and adapted to complex waste matrices.

\section{Acknowledgements}

Nicole D. Berge acknowledges the support of the National Science Foundation under Grant No. 1510869. Any opinions, findings, and conclusions or recommendations expressed in this material are those of the author(s) and do not necessarily reflect the views of the National Science Foundation. Marion Huber-Humer and Florian Part acknowledge the Austrian Federal Ministry of Agriculture, Forestry, Environment and Water Management (BMLFUW) and the Austrian Ministry for Transport, Innovation and Technology (BMVIT) for supporting the project No. 857174, which is part of the "NANO Environment Health and Safety program." Pierre Hennebert acknowledges the support of the French Ministry for Environment for supporting the program DRC54. Peter Quicker and Paweł Baran acknowledge the support of the German Federal Ministry for Education and Research (BMBF) for supporting the project "NanoEmission."

\section{References}

Abreu, A. S.; Oliveira, M.; Machado, A. V. (2015). Effect of clay mineral addition on properties of bio-based polymer blends. Applied Clay Science 104: 277-285.

Adam, V.; Nowack, B. (2017). European country-specific probabilistic assessment of nanomaterial flows towards landfilling, incineration and recycling. Environmental Science: Nano 4(10): 1961-1973.

Akaighe, N.; MacCuspie, R. I.; Navarro, D. A.; Aga, D. S.; Banerjee, S.; Sohn, M.; Sharma, V. K. (2011). Humic Acid-Induced Silver Nanoparticle Formation Under Environmentally Relevant Conditions. Environ. Sci. Technol. 45(9): 3895-3901.

Al-Kattan, A.; Wichser, A.; Vonbank, R.; Brunner, S.; Ulrich, A.; Zuin, S.; Arroyo, Y.; Golanski, L.; Nowack, B. (2015). Characterization of materials released into water from paint containing nano-SiO2. Chemosphere 119: 1314-1321.

Al-Kattan, A.; Wichser, A.; Vonbank, R.; Brunner, S.; Ulrich, A.; Zuin, S.; Nowack, B. (2013). Release of $\mathrm{TiO} 2$ from paints containing pigment-TiO2 or nano-TiO2 by weathering. Environmental Science: Processes \& Impacts 15(12): 2186-2193.

Al-Kattan, A.; Wichser, A.; Zuin, S.; Arroyo, Y.; Golanski, L.; Ulrich, A.; Nowack, B. (2014). Behavior of TiO2 Released from Nano-TiO2-Containing Paint and Comparison to Pristine Nano-TiO2. Environmental Science \& Technology 48(12): 6710-6718.

Arvidsson, R.; Molander, S.; Sandén, B. A. (2012). Particle Flow Analysis. Journal of Industrial Ecology 16(3): 343-351. 
1111

1112

1113

1114

Balaguer, M. P.; Aliaga, C.; Fito, C.; Hortal, M. (2016). Compostability assessment of nano-reinforced poly(lactic acid) films. Waste Management 48: 143-155.

Baran, P.; Quicker, P. (2016). Verbleib und Verhalten von Nanopartikeln bei der Abfallverbrennung (in German). Österreichische Wasser- und Abfallwirtschaft, Springer Vienna, P. 1-15. doi 10.1007/s00506-016-0362-z.

Baumann, T.; Fruhstorfer, P.; Klein, T.; Niessner, R. (2006). Colloid and heavy metal transport at landfill sites in direct contact with groundwater. Water Research 40(14): 2776-2786.

Baun, A.; Hartmann, N. B.; Grieger, K.; Kusk, K. O. (2008). Ecotoxicity of engineered nanoparticles to aquatic invertebrates: a brief review and recommendations for future toxicity testing. Ecotoxicology 17(5): 387-395.

Bello, D.; Wardle, B.; Yamamoto, N.; Guzman deVilloria, R.; Garcia, E.; Hart, A.; Ahn, K.; Ellenbecker, M.; Hallock, M. (2009). Exposure to nanoscale particles and fibers during machining of hybrid advanced composites containing carbon nanotubes. Journal of Nanoparticle Research 11(1): 231-249.

Bello, D.; Wardle, B. L.; Zhang, J.; Yamamoto, N.; Santeufemio, C.; Hallock, M.; Virji, M. A. (2010). Characterization of Exposures To Nanoscale Particles and Fibers During Solid Core Drilling of Hybrid Carbon Nanotube Advanced Composites. International Journal of Occupational and Environmental Health 16(4): 434-450.

Benn, T.; Cavanagh, B.; Hristovski, K.; Posner, J. D.; Westerhoff, P. (2010). The release of nanosilver from consumer products used in the home Journal of Environmental Quality 39(6): 1875-1882.

Benn, T. M.; Westerhoff, P. (2008a). Nanoparticle silver released into water from commercially available sock fabrics. Environmental Science \& Technology 42(11): 4133-4139.

Benn, T. M.; Westerhoff, P. (2008b). Nanoparticle silver released into water from commercially available sock fabrics. Environ Sci Technol 42.

Bitinis, N.; Fortunati, E.; Verdejo, R.; Bras, J.; Kenny, J. M.; Torre, L.; López-Manchado, M. A. (2013). Poly(lactic acid)/natural rubber/cellulose nanocrystal bionanocomposites. Part II: Properties evaluation. Carbohydrate Polymers 96(2): 621-627.

Blasco, C.; Picó, Y. (2011). Determining nanomaterials in food. TrAC Trends in Analytical Chemistry 30(1): 84-99.

Boldrin, A.; Hansen, S. F.; Baun, A.; Hartmann, N. I. B.; Astrup, T. F. (2014). Environmental exposure assessment framework for nanoparticles in solid waste. Journal of Nanoparticle Research 16(6): 2394.

Bolyard, S. C.; Reinhart, D. R.; Santra, S. (2013). Behavior of Engineered Nanoparticles in Landfill Leachate. Environmental Science \& Technology 47(15): 8114-8122.

Boonruksa, P.; Bello, D.; Zhang, J.; Isaacs, J. A.; Mead, J. L.; Woskie, S. R. (2016a). Characterization of Potential Exposures to Nanoparticles and Fibers during Manufacturing and Recycling of Carbon Nanotube Reinforced Polypropylene Composites. Annals of Occupational Hygiene 60(1): 40-55.

Boonruksa, P.; Bello, D.; Zhang, J.; Isaacs, J. A.; Mead, J. L.; Woskie, S. R. (2016b). Exposures to nanoparticles and fibers during injection molding and recycling of carbon nanotube reinforced polycarbonate composites. J Expo Sci Environ Epidemiol.

Börner, R.; Meiller, M.; Oischinger, J.; Daschner, R. (2016). Untersuchung möglicher Umweltauswirkungen bei der Entsorgung nanomaterialhaltiger Abfälle in Abfallbehandlungsanlagen (in German). 
Bouillard, J.; R'Mili, B.; Moranviller, D.; Vignes, A.; Le Bihan, O.; Ustache, A.; Bomfim, J. S.; Frejafon, E.; Fleury, D. (2013). Nanosafety by design: risks from nanocomposite/nanowaste combustion. Journal of Nanoparticle Research 15(4): 1-11. (2006). In vitro cytotoxicity of oxide nanoparticles: comparison to asbestos, silica, and the effect of particle solubility. Environ Sci Technol 40(14): 4374-4381.

Buffat, P.; Borel, J. P. (1976). Size effect on the melting temperature of gold particles. Physical Review $A$ 13(6): 2287-2298.

Buha, J.; Mueller, N.; Nowack, B.; Ulrich, A.; Losert, S.; Wang, J. (2014). Physical and Chemical in the Nanometer Range. Environmental Science \& Technology 48(9): 4765-4773.

Bumbudsanpharoke, N.; Ko, S. (2015). Nano-Food Packaging: An Overview of Market, Migration Research, current data useful for material flow modeling? Environmental Pollution 213: 502-517. recycling process in Switzerland. Waste Management 36(0): 33-43.

Center for food safety. (2014). "Nano-silver in food and food contact products." Toxicogenomic responses of the model legume medicago truncatula to aged biosolids containing a mixture of nanomaterials ( $\mathrm{TiO} 2, \mathrm{Ag}$, and $\mathrm{ZnO}$ ) from a pilot wastewater treatment plant. Environmental Science \& Technology 49(14): 8759-8768.

Chen, J.; Tang, Y. Q.; Li, Y.; Nie, Y.; Hou, L.; Li, X. Q.; Wu, X. L. (2014). Impacts of different nanoparticles on functional bacterial community in activated sludge. Chemosphere 104: 141-148. Langmuir 22(26): 10994-11001. nanoparticles, silver ions, and silver chloride colloids on microbial growth. Water Research 42(12): 3066-3074. bacteria. Environ Sci Technol 42(12): 4583-4588. 7988-7997.

Colman, B. P.; Arnaout, C. L.; Anciaux, S.; Gunsch, C. K.; Hochella, M. F.; Kim, B.; Lowry, G. V.; McGill, B. M.; Reinsch, B. C.; Richardson, C. J.; Unrine, J. M.; Wright, J. P.; Yin, L. Y.; Bernhardt, E. S. (2013). Low concentrations of silver nanoparticles in biosolids cause adverse ecosystem responses under realistic field scenario. Plos One 8(2). 
CPI Consumer Products Inventory. An inventory of nanotechnology-based consumer products introduced on the market. Project on Emerging Nanotechnologies. Woodrow Wilson International Center for Scholars. http://www.nanotechproject.org/cpi/ (last access on January 4, 2018).

Dale, A. L.; Casman, E. A.; Lowry, G. V.; Lead, J. R.; Viparelli, E.; Baalousha, M. (2015). Modeling Nanomaterial Environmental Fate in Aquatic Systems. Environmental Science \& Technology 49(5): 2587-2593.

Demirel, B. (2016). The impacts of engineered nanomaterials (ENMs) on anaerobic digestion processes. Process Biochemistry 51(2): 308-313.

Ding, Y.; Kuhlbusch, T. A. J.; Van Tongeren, M.; Jiménez, A. S.; Tuinman, I.; Chen, R.; Alvarez, I. L.; Mikolajczyk, U.; Nickel, C.; Meyer, J.; Kaminski, H.; Wohlleben, W.; Stahlmecke, B.; Clavaguera, S.; Riediker, M. (2017). Airborne engineered nanomaterials in the workplace-a review of release and worker exposure during nanomaterial production and handling processes. Journal of Hazardous Materials 322 , Part A: 17-28.

Dulger, M.; Sakallioglu, T.; Temizel, I.; Demirel, B.; Copty, N. K.; Onay, T. T.; Uyguner-Demirel, C. S.; Karanfil, T. (2016). Leaching potential of nano-scale titanium dioxide in fresh municipal solid waste. Chemosphere 144(Supplement C): 1567-1572.

Duncan, T. V. (2011). Applications of nanotechnology in food packaging and food safety: barrier materials, antimicrobials and sensors. J Colloid Interface Sci 363(1): 1-24.

Duncan, T. V.; Pillai, K. (2015). Release of Engineered Nanomaterials from Polymer Nanocomposites: Diffusion, Dissolution, and Desorption. ACS Applied Materials \& Interfaces 7(1): 2-19.

Durán, N.; Marcato, P. D.; De Souza, G. I. H.; Alves, O. L.; Esposito, E. (2007). Antibacterial Effect of Silver Nanoparticles Produced by Fungal Process on Textile Fabrics and Their Effluent Treatment. Journal of Biomedical Nanotechnology 3(2): 203-208.

EC (2011). COMMISSION RECOMMENDATION of 18 October 2011 on the definition of nanomaterial (Text with EEA relevance). (2011/696/EU). Official Journal of the European Union. European Commission.

EC (2012). Types and uses of nanomaterials, including safety aspects. Accompanying the Communication from the Commission to the European Parliament, the Council and the European Economic and Social Committee on the Second Regulatory Review on Nanomaterials. COM(2012) 572 final\}. European Commission.

Fabrega, J.; Renshaw, J. C.; Lead, J. R. (2009). Interactions of Silver Nanoparticles with Pseudomonas putida Biofilms. Environmental Science \& Technology 43(23): 9004-9009.

Forster, H.; Thajudeen, T.; Funk, C.; Peukert, W. (2016). Separation of nanoparticles: Filtration and scavenging from waste incineration plants. Waste Manag 52: 346-352.

Fortunati, E.; Rinaldi, S.; Peltzer, M.; Bloise, N.; Visai, L.; Armentano, I.; Jiménez, A.; Latterini, L.; Kenny, J. M. (2014). Nano-biocomposite films with modified cellulose nanocrystals and synthesized silver nanoparticles. Carbohydrate Polymers 101: 1122-1133.

Froggett, S. J.; Clancy, S. F.; Boverhof, D. R.; Canady, R. A. (2014). A review and perspective of existing research on the release of nanomaterials from solid nanocomposites. Part Fibre Toxicol 11: 17.

Fu, G.; Vary, P. S.; Lin, C.-T. (2005). Anatase TiO2 Nanocomposites for Antimicrobial Coatings. The Journal of Physical Chemistry B 109(18): 8889-8898. 
Fukushima, K.; Abbate, C.; Tabuani, D.; Gennari, M.; Camino, G. (2009). Biodegradation of poly(lactic acid) and its nanocomposites. Polymer Degradation and Stability 94(10): 1646-1655.

Ge, Y.; Schimel, J. P.; Holden, P. A. (2011). Evidence for Negative Effects of TiO2 and ZnO Nanoparticles on Soil Bacterial Communities. Environmental Science \& Technology 45(4): 1659-1664.

Geranio, L.; Heuberger, M.; Nowack, B. (2009). The behavior of silver nanotextiles during washing. Environ Sci Technol 43.

Ghosh, S.; Mashayekhi, H.; Pan, B.; Bhowmik, P.; Xing, B. (2008). Colloidal Behavior of Aluminum Oxide Nanoparticles As Affected by pH and Natural Organic Matter. Langmuir 24(21): 12385-12391.

Gitipour, A.; El Badawy, A.; Arambewela, M.; Miller, B.; Scheckel, K.; Elk, M.; Ryu, H.; Gomez-Alvarez, V.; Domingo, J. S.; Thiel, S.; Tolaymat, T. (2013). The impact of silver nanoparticles on the composting of municipal solid waste. Environmental Science \& Technology 47(24): 14385-14393.

Golanski, L.; Guiot, A.; Pras, M.; Malarde, M.; Tardif, F. (2012). Release-ability of nano fillers from different nanomaterials (toward the acceptability of nanoproduct). Journal of Nanoparticle Research 14(7): 962.

Gonzalez-Estrella, J.; Puyol, D.; Gallagher, S.; Sierra-Alvarez, R.; Field, J. A. (2015). Elemental copper nanoparticle toxicity to different trophic groups involved in anaerobic and anoxic wastewater treatment processes. Sci Total Environ 512-513: 308-315.

Gonzalez-Estrella, J.; Sierra-Alvarez, R.; Field, J. A. (2013). Toxicity assessment of inorganic nanoparticles to acetoclastic and hydrogenotrophic methanogenic activity in anaerobic granular sludge. $J$ Hazard Mater 260: 278-285.

Gottschalk, F.; Lassen, C.; Kjoelholt, J.; Christensen, F.; Nowack, B. (2015). Modeling Flows and Concentrations of Nine Engineered Nanomaterials in the Danish Environment. International Journal of Environmental Research and Public Health 12(5): 5581.

Gottschalk, F.; Ort, C.; Scholz, R. W.; Nowack, B. (2011). Engineered nanomaterials in rivers - Exposure scenarios for Switzerland at high spatial and temporal resolution. Environmental Pollution 159(12): 3439-3445.

Gottschalk, F.; Scholz, R. W.; Nowack, B. (2010). Probabilistic material flow modeling for assessing the environmental exposure to compounds: Methodology and an application to engineered nano-TiO2 particles. Environmental Modelling \&amp; Software 25(3): 320-332.

Gottschalk, F.; Sonderer, T.; Scholz, R. W.; Nowack, B. (2009a). Modeled environmental concentrations of engineered nanomaterials ( $\mathrm{TiO} 2, \mathrm{ZnO}, \mathrm{Ag}, \mathrm{CNT}$, fullerenes) for different regions. Environmental Science and Technology 43(24): 9216-9222.

Gottschalk, F.; Sonderer, T.; Scholz, R. W.; Nowack, B. (2009b). Modeled environmental concentrations of engineered nanomaterials (TiO2, $\mathrm{ZnO}, \mathrm{Ag}, \mathrm{CNT}$, fullerenes) for different regions. Environ Sci Technol 43.

Gounaris, V.; Anderson, P. R.; Holsen, T. M. (1993). Characteristics and environmental significance of colloids in landfill leachate. Environmental Science \& Technology 27(7): 1381-1387.

Greßler, S.; Gazsó, A. (2014). Nano-Konsumprodukte in Österreich - Aktualisierung und Adaptierung der NanoTrust-Datenbank (NanoTrust-Dossier Nr. 041 - November 2014). Wien, Institut für Technikfolgen-Abschätzung (ITA). 
Hansen, S. F.; Heggelund, L. R.; Revilla Besora, P.; Mackevica, A.; Boldrin, A.; Baun, A. (2016). Nanoproducts - what is actually available to European consumers? Environmental Science: Nano 3(1): 169-180.

Heggelund, L.; Hansen, S. F.; Astrup, T. F.; Boldrin, A. (2016). Semi-quantitative analysis of solid waste flows from nano-enabled consumer products in Europe, Denmark and the United Kingdom - Abundance, distribution and management. Waste Management 56: 584-592.

Heinlaan, M.; Ivask, A.; Blinova, I.; Dubourguier, H.-C.; Kahru, A. (2008). Toxicity of nanosized and bulk $\mathrm{ZnO}, \mathrm{CuO}$ and $\mathrm{TiO} 2$ to bacteria Vibrio fischeri and crustaceans Daphnia magna and Thamnocephalus platyurus. Chemosphere 71(7): 1308-1316.

Hendren, C. O.; Mesnard, X.; Dröge, J.; Wiesner, M. R. (2011). Estimating Production Data for Five Engineered Nanomaterials As a Basis for Exposure Assessment. Environmental Science \& Technology 45(9): 4190-4190.

Hennebert, P.; Avellan, A.; Yan, J.; Aguerre-Chariol, O. (2013). Experimental evidence of colloids and nanoparticles presence from 25 waste leachates. Waste Management 33(9): 1870-1881.

Hincapié, I.; Caballero-Guzman, A.; Hiltbrunner, D.; Nowack, B. (2015). Use of engineered nanomaterials in the construction industry with specific emphasis on paints and their flows in construction and demolition waste in Switzerland. Waste Management 43: 398-406.

Hotze, E. M.; Phenrat, T.; Lowry, G. V. (2010). Nanoparticle Aggregation: Challenges to Understanding Transport and Reactivity in the Environment All rights reserved. No part of this periodical may be reproduced or transmitted in any form or by any means, electronic or mechanical, including photocopying, recording, or any information storage and retrieval system, without permission in writing from the publisher. Journal of Environmental Quality 39(6): 1909-1924.

Hsiao, I. L.; Huang, Y.-J. (2011). Effects of various physicochemical characteristics on the toxicities of ZnO and $\mathrm{TiO} 2$ nanoparticles toward human lung epithelial cells. Science of The Total Environment 409(7): $1219-1228$.

Jensen, D. L.; Christensen, T. H. (1999). Colloidal and dissolved metals in leachates from four Danish landfills. Water Research 33(9): 2139-2147.

Johansen, A.; Pedersen, A. L.; Jensen, K. A.; Karlson, U.; Hansen, B. M.; Scott-Fordsmand, J. J.; Winding, A. (2008). Effects of $\mathrm{C} 60$ fullerene nanoparticles on soil bacteria and protozoans. Environmental Toxicology and Chemistry 27(9): 1895-1903.

Judy, J. D.; McNear, D. H.; Chen, C.; Lewis, R. W.; Tsyusko, O. V.; Bertsch, P. M.; Rao, W.; Stegemeier, J.; Lowry, G. V.; McGrath, S. P.; Durenkamp, M.; Unrine, J. M. (2015). Nanomaterials in biosolids inhibit nodulation, shift microbial community composition, and result in increased metal uptake relative to bulk/dissolved metals. Environmental Science \& Technology 49(14): 8751-8758.

Judy, J. D.; Unrine, J. M.; Rao, W.; Wirick, S.; Bertsch, P. M. (2012). Bioavailability of gold nanomaterials to plants: Importance of particle size and surface coating. Environmental Science \& Technology 46(15): 8467-8474.

Kaegi, R.; Englert, A.; Gondikas, A.; Sinnet, B.; von der Kammer, F.; Burkhardt, M. (2017). Release of TiO2 - (Nano) particles from construction and demolition landfills. Nanolmpact 8(Supplement C): 73-79.

Kaegi, R.; Ulrich, A.; Sinnet, B.; Vonbank, R.; Wichser, A.; Zuleeg, S.; Simmler, H.; Brunner, S.; Vonmont, H.; Burkhardt, M.; Boller, M. (2008). Synthetic TiO2 nanoparticle emission from exterior facades into the aquatic environment. Environmental Pollution 156(2): 233-239. 

Regional to Local. Environmental Science \& Technology Letters 1(1): 65-70.

1313 Keller, A. A.; McFerran, S.; Lazareva, A.; Suh, S. (2013). Global life cycle releases of engineered nanomaterials. Journal of Nanoparticle Research 15(6): 1692. and Cell Death. Nanomaterials 5(3): 1163. Nanoparticles in Final Sewage Sludge Products. Environ. Sci. Technol. 44(19): 7509-7514. Sultan, Y.; Vejins, V.; Wohlleben, W. (2014). Release characteristics of selected carbon nanotube polymer composites. Carbon 68: 33-57. nanomaterial removal and release from wastewater treatment plants. Environ Sci Technol 43. Long-Term Composition of MSW Landfill Leachate: A Review. Critical Reviews in Environmental Science and Technology 32(4): 297-336. nanotubes throughout the application life cycle. Journal of Cleaner Production 16(8-9): 927-937.

Köster, R.; Wagner, T.; Delay, M.; Frimmel, F. H. (2007). Release of Contaminants from Bottom Ashes Colloid Facilitated Transport and Colloid Trace Analysis by Means of Laser-Induced Breakdown Detection (LIBD). Colloidal Transport in Porous Media. F. H. Frimmel, F. Von Der Kammer and H.-C. Flemming. Berlin, Heidelberg, Springer Berlin Heidelberg: 251-272.

Kumar, P.; Pirjola, L.; Ketzel, M.; Harrison, R. M. (2013). Nanoparticle emissions from 11 non-vehicle exhaust sources - A review. Atmospheric Environment 67(0): 252-277.

Kumar, R.; Howdle, S.; Munstedt, H. (2005). Polyamide/silver antimicrobials: effect of filler types on the silver ion release. J Biomed Mater Res B Appl Biomater 75(2): 311-319.

Laborda, F.; Bolea, E.; Cepriá, G.; Gómez, M. T.; Jiménez, M. S.; Pérez-Arantegui, J.; Castillo, J. R. (2016). Detection, characterization and quantification of inorganic engineered nanomaterials: $A$ review of techniques and methodological approaches for the analysis of complex samples. Analytica Chimica Acta 904: 10-32.

Lang, I. M.; Hauser, M.; Baumann, W.; Mätzing, H.; Paur, H. R.; Seifert, H. (2015). Freisetzung von Nanopartikeln bei der Abfallverbrennung (in German). In: Thome-Kozmiensky K.J., Beckmann M. Energie aus Abfall, Band 12, TK Verlag Karl Thome-Kozmensky, Neuruppin, P 347-370. compounds on nanoparticle TiO2 (n-TiO2) aggregation. Chemosphere 154: 187-193. 
Lee, J.; Bartelt-Hunt, S. L.; Li, Y.; Morton, M. (2015). Effect of $17 \beta$-estradiol on stability and mobility of TiO 2 rutile nanoparticles. Science of The Total Environment 511: 195-202.

1353

Lesyuk, R.; Petrowska, H.; Kravchuk, O.; Bobitski, Y.; Kotlyarchuk, B. (2015). Nanomaterials for Ink-Jet Printed Electronics. Nanoplasmonics, Nano-Optics, Nanocomposites, and Surface Studies: Selected Proceedings of the Second FP7 Conference and the Third International Summer School Nanotechnology: From Fundamental Research to Innovations, August 23-30, 2014, Yaremche-Lviv, Ukraine. O. Fesenko and L. Yatsenko. Cham, Springer International Publishing: 445-455.

Levard, C.; Hotze, E. M.; Lowry, G. V.; Brown, G. E. (2012). Environmental Transformations of Silver Nanoparticles: Impact on Stability and Toxicity. Environmental Science \& Technology 46(13): 6900-6914.

Li, D.; Li, B.; Wang, Q.; Hou, N.; Li, C.; Cheng, X. (2016). Toxicity of TiO2 nanoparticle to denitrifying strain CFY1 and the impact on microbial community structures in activated sludge. Chemosphere 144: 1334-1341.

Li, R.; Yue, D.; Liu, J.; Nie, Y. (2009). Size fractionation of organic matter and heavy metals in raw and treated leachate. Waste Management 29(9): 2527-2533.

Li, Y.; Wang, Y.; Pennell, K. D.; Abriola, L. M. (2008). Investigation of the Transport and Deposition of Fullerene (C60) Nanoparticles in Quartz Sands under Varying Flow Conditions. Environmental Science \& Technology 42(19): 7174-7180.

Limbach, L. K.; Wick, P.; Manser, P.; Grass, R. N.; Bruinink, A.; Stark, W. J. (2007). Exposure of Engineered Nanoparticles to Human Lung Epithelial Cells: Influence of Chemical Composition and Catalytic Activity on Oxidative Stress. Environmental Science \& Technology 41(11): 4158-4163.

Llorens, A.; Lloret, E.; Picouet, P. A.; Trbojevich, R.; Fernandez, A. (2012). Metallic-based micro and nanocomposites in food contact materials and active food packaging. Trends in Food Science \& Technology 24(1): 19-29.

Lombi, E.; Donner, E.; Taheri, S.; Tavakkoli, E.; Jämting, A. K.; McClure, S.; Naidu, R.; Miller, B. W.; Scheckel, K. G.; Vasilev, K. (2013a). Transformation of four silver/silver chloride nanoparticles during anaerobic treatment of wastewater and post-processing of sewage sludge. Environmental Pollution 176(0): 193-197.

Lombi, E.; Donner, E.; Taheri, S.; Tavakkoli, E.; Jämting, A. K.; McClure, S.; Naidu, R.; Miller, B. W.; Scheckel, K. G.; Vasilev, K. (2013b). Transformation of four silver/silver chloride nanoparticles during anaerobic treatment of wastewater and post-processing of sewage sludge. Environmental Pollution 176: 193-197.

Lombi, E.; Donner, E.; Tavakkoli, E.; Turney, T. W.; Naidu, R.; Miller, B. W.; Scheckel, K. G. (2012). Fate of zinc oxide nanoparticles during anaerobic digestion of wastewater and post-treatment processing of sewage sludge. Environmental Science \& Technology 46(16): 9089-9096.

Lorenz, C.; Windler, L.; von Goetz, N.; Lehmann, R. P.; Schuppler, M.; Hungerbühler, K.; Heuberger, M.; Nowack, B. (2012). Characterization of silver release from commercially available functional (nano)textiles. Chemosphere 89(7): 817-824.

Louie, S. M.; Tilton, R. D.; Lowry, G. V. (2016). Critical review: impacts of macromolecular coatings on critical physicochemical processes controlling environmental fate of nanomaterials. Environmental Science: Nano.

Lowry, G. V.; Espinasse, B. P.; Badireddy, A. R.; Richardson, C. J.; Reinsch, B. C.; Bryant, L. D.; Bone, A. J.; Deonarine, A.; Chae, S.; Therezien, M.; Colman, B. P.; Hsu-Kim, H.; Bernhardt, E. S.; Matson, C. W.; Wiesner, M. R. (2012a). Long-Term Transformation and Fate of Manufactured Ag Nanoparticles in a 

7027-7036.

Lowry, G. V.; Gregory, K. B.; Apte, S. C.; Lead, J. R. (2012b). Transformations of Nanomaterials in the Environment. Environmental Science \& Technology 46(13): 6893-6899.

Lowry, G. V.; Hotze, E. M.; Bernhardt, E. S.; Dionysiou, D. D.; Pedersen, J. A.; Wiesner, M. R.; Xing, B. (2010). Environmental occurrences, behavior, fate, and ecological effects of nanomaterials: an introduction to the special series. J Environ Qual 39(6): 1867-1874.

Lozano, P.; Berge, N. D. (2012). Single-walled carbon nanotube behavior in representative mature leachate. Waste Management 32(9): 1699-1711.

Luoma, S. N. (2008). Silver nanotechnologies and the environment: old problems or new challenges? Washington DC.

Lyon, D. Y.; Fortner, J. D.; Sayes, C. M.; Colvin, V. L.; Hughe, J. B. (2005). Bacterial cell association and antimicrobial activity of a C60 water suspension. Environ Toxicol Chem 24(11): 2757-2762.

Ma, R.; Levard, C.; Judy, J. D.; Unrine, J. M.; Durenkamp, M.; Martin, B.; Jefferson, B.; Lowry, G. V. (2014). Fate of zinc oxide and silver nanoparticles in a pilot wastewater treatment plant and in processed biosolids. Environmental Science \& Technology 48(1): 104-112.

Mackevica, A.; Foss Hansen, S. (2016). Release of nanomaterials from solid nanocomposites and consumer exposure assessment - a forward-looking review. Nanotoxicology 10(6): 641-653.

Mahaye, N.; Thwala, M.; Cowan, D. A.; Musee, N. (2017). Genotoxicity of metal based engineered nanoparticles in aquatic organisms: A review. Mutation Research/Reviews in Mutation Research 773: 134-160.

Maiti, P.; Batt, C. A.; Giannelis, E. P. (2007). New biodegradable polyhydroxybutyrate/layered silicate nanocomposites. Biomacromolecules 8(11): 3393-3400.

Maiti, S.; Ray, D.; Mitra, D.; Misra, M. (2012). Study of compostable behavior of jute nano fiber reinforced biocopolyester composites in aerobic compost environment. Journal of Applied Polymer Science 123(5): 2952-2958.

Mattsson, M.-O.; Simkó, M. (2017). The changing face of nanomaterials: Risk assessment challenges along the value chain. Regulatory Toxicology and Pharmacology 84: 105-115.

Matura, M.; Ettler, V.; Klementova, M. (2012). Transmission electron microscopy investigation of colloids and particles from landfill leachates. Waste Manag Res 30(5): 530-541.

McCarthy, J. F.; Zachara, J. M. (1989). Subsurface transport of contaminants. Environmental Science \& Technology 23(5): 496-502.

Mehrabi, K.; Nowack, B.; Arroyo Rojas Dasilva, Y.; Mitrano, D. M. (2017). Improvements in Nanoparticle Tracking Analysis To Measure Particle Aggregation and Mass Distribution: A Case Study on Engineered Nanomaterial Stability in Incineration Landfill Leachates. Environmental Science \& Technology 51(10): 5611-5621.

Meima, J. A.; Comans, R. N. J. (1999). The leaching of trace elements from municipal solid waste incinerator bottom ash at different stages of weathering. Applied Geochemistry 14(2): 159-171. 

characterization of potential sources of worker exposure to carbon nanofibers during polymer composite laboratory operations. J Occup Environ Hyg 4(12): D125-130. through the life cycle: releases from landfilling after washing. Environmental Science: Nano. leachates from landfills containing waste incineration residues. Environmental Science: Nano. transformations through the life cycle of nano-enhanced products. Environ Int 77: 132-147. Nanoparticles in Wash Water from Conventional Silver and Nano-silver Textiles. ACS Nano 8(7): 7208-7219.

Mu, H.; Chen, Y.; Xiao, N. (2011). Effects of metal oxide nanoparticles (TiO2, Al2O3, SiO2 and ZnO) on waste activated sludge anaerobic digestion. Bioresource Technology 102(22): 10305-10311. nanomaterials during waste handling. Environmental Science: Processes \& Impacts 15(1): 251-259.

Mueller, N. C.; Nowack, B.; Wang, J.; Ulrich, A.; Buha, J. (2012). Nanomaterials in waste incineration and landfills. Internal Empa-report, Empa-Swiss Federal Laboratories for Materials Science and Technology. current tools adequate? Human \& Experimental Toxicology 30(8): 820-835.

Musee, N. (2011b). Nanowastes and the environment: Potential new waste management paradigm. Environ 1454 Int 37(1): 112-128.

Musee, N. (2011c). Simulated environmental risk estimation of engineered nanomaterials: a case of cosmetics in Johannesburg City. Hum Exp Toxicol 30(9): 1181-1195.

Musee, N. (2017). A model for screening and prioritizing consumer nanoproduct risks: A case study from

Nanda, K. K. (2009). Size-dependent melting of nanoparticles: Hundred years of thermodynamic model.

nanodb.dk The Nanodatabase. Your inventory for products that contain Nanomaterials. DTU Environment, the Danish Ecological Council and Danish Consumer Council. http://nanodb.dk/ (last access on January 4, 2018).

Nguyen, D.; Visvanathan, C.; Jacob, P.; Jegatheesan, V. (2015). Effects of nano cerium (IV) oxide and zinc 1466 oxide particles on biogas production. International Biodeterioration \& Biodegradation 102(Supplement C): 165-171.

Nguyen, T.; Pellegrin, B.; Bernard, C.; Rabb, S.; Stuztman, P.; Gorham, J. M.; Gu, X.; Yu, L. L.; Chin, J. W. (2012). Characterization of Surface Accumulation and Release of Nanosilica During Irradiation of Polymer Nanocomposites by Ultraviolet Light. Journal of Nanoscience and Nanotechnology 12(8): 6202-6215. 
Nowack, B.; Baalousha, M.; Bornhoft, N.; Chaudhry, Q.; Cornelis, G.; Cotterill, J.; Gondikas, A.; Hassellov, M.; Lead, J.; Mitrano, D. M.; von der Kammer, F.; Wontner-Smith, T. (2015). Progress towards the validation of modeled environmental concentrations of engineered nanomaterials by analytical measurements. Environmental Science: Nano.

Nowack, B.; Ranville, J. F.; Diamond, S.; Gallego-Urrea, J. A.; Metcalfe, C.; Rose, J.; Horne, N.; Koelmans, A. A.; Klaine, S. J. (2012). Potential scenarios for nanomaterial release and subsequent alteration in the environment. Environmental Toxicology and Chemistry 31(1): 50-59.

\section{OECD (2015). RECYCLING OF WASTE CONTAINING NANOMATERIALS.} ENV/EPOC/WPRPW(2013)2/FINAL. Working Party on Resource Productivity and Waste. Organisation for Economic Co-operation and Development (OECD).

Olabarrieta, J.; Zorita, S.; Peña, I.; Rioja, N.; Monzón, O.; Benguria, P.; Scifo, L. (2012). Aging of photocatalytic coatings under a water flow: Long run performance and TiO2 nanoparticles release. Applied Catalysis B: Environmental 123-124(0): 182-192.

Otero-González, L.; Field, J. A.; Sierra-Alvarez, R. (2014). Inhibition of anaerobic wastewater treatment after long-term exposure to low levels of CuO nanoparticles. Water Research 58: 160-168.

Ounoughene, G.; Le Bihan, O.; Chivas-Joly, C.; Motzkus, C.; Longuet, C.; Debray, B.; Joubert, A.; Le Coq, L.; Lopez-Cuesta, J. M. (2015). Behavior and Fate of Halloysite Nanotubes (HNTs) When Incinerating PA6/HNTs Nanocomposite. Environ Sci Technol 49(9): 5450-5457.

Øygard, J. K.; Opedal, E. H. (2007). Assessment of dissolved and non-dissolved metals in aerated landfill leachate. Fresenius Environmental Bulletin 16(11 B): 1451-1456.

Part, F. (2016). Strategies and nanotechnology tools for identification and characterization of molecular interactions in complex matrices: analysis of the fate and transport of engineered nanomaterials in selected waste streams. Doctoral thesis, University of Natural Resources and Life Sciences, Vienna. 198.

Part, F.; Gruber, I.; Hänel, K.; Huber-Humer, M. (2017). Synthetisch hergestellte Nanomaterialien in Konsumprodukten und deren Verbleib am Ende ihrer Nutzungsphase. Österreichische Wasser- und Abfallwirtschaft 69(1): 43-50.

Part, F.; Huber-Humer, M.; Berge, N. D. (2016a). Engineered nanomaterials in waste streams. Waste Management 51: 1-2.

Part, F.; Zaba, C.; Bixner, O.; Zafiu, C.; Hann, S.; Sinner, E. K.; Huber-Humer, M. (2016b). Traceability of fluorescent engineered nanomaterials and their fate in complex liquid waste matrices. Environ Pollut 214: 795-805.

Part, F.; Zecha, G.; Causon, T.; Sinner, E.-K.; Huber-Humer, M. (2015). Current limitations and challenges in nanowaste detection, characterisation and monitoring. Waste Management 43: 407-420.

Pasricha, A.; Jangra, S. L.; Singh, N.; Dilbaghi, N.; Sood, K. N.; Arora, K.; Pasricha, R. (2012). Comparative study of leaching of silver nanoparticles from fabric and effective effluent treatment. Journal of Environmental Sciences 24(5): 852-859.

Pati, P.; McGinnis, S.; Vikesland, P. J. (2016). Waste not want not: life cycle implications of gold recovery and recycling from nanowaste. Environmental Science: Nano 3(5): 1133-1143.

Peijnenburg, W.; Praetorius, A.; Scott-Fordsmand, J.; Cornelis, G. (2016). Fate assessment of engineered nanoparticles in solids dominated media - Current insights and the way forward. Environmental Pollution 218: 1365-1369. 
Peijnenburg, W. J. G. M.; Baalousha, M.; Chen, J.; Chaudry, Q.; Von Der Kammer, F.; Kuhlbusch, T. A. J.; Lead, J.; Nickel, C.; Quik, J. T. K.; Renker, M.; Wang, Z.; Koelmans, A. A. (2015). A review of the properties and processes determining the fate of engineered nanomaterials in the aquatic environment. Critical Reviews in Environmental Science and Technology: 00-00.

Petersen, E. J.; Lam, T.; Gorham, J. M.; Scott, K. C.; Long, C. J.; Stanley, D.; Sharma, R.; Alexander Liddle, J.; Pellegrin, B.; Nguyen, T. (2014). Methods to assess the impact of UV irradiation on the surface chemistry and structure of multiwall carbon nanotube epoxy nanocomposites. Carbon 69: 194-205.

Petosa, A. R.; Jaisi, D. P.; Quevedo, I. R.; Elimelech, M.; Tufenkji, N. (2010). Aggregation and Deposition of Engineered Nanomaterials in Aquatic Environments: Role of Physicochemical Interactions. Environmental Science \& Technology 44(17): 6532-6549.

Phenrat, T.; Song, J. E.; Cisneros, C. M.; Schoenfelder, D. P.; Tilton, R. D.; Lowry, G. V. (2010). Estimating Attachment of Nano- and Submicrometer-particles Coated with Organic Macromolecules in Porous Media: Development of an Empirical Model. Environmental Science \& Technology 44(12): 4531-4538.

Piccinno, F.; Gottschalk, F.; Seeger, S.; Nowack, B. (2012). Industrial production quantities and uses of ten engineered nanomaterials in Europe and the world. Journal of Nanoparticle Research 14(9): 1-11.

Praetorius, A.; Scheringer, M.; Hungerbühler, K. (2012). Development of Environmental Fate Models for Engineered Nanoparticles-A Case Study of TiO2 Nanoparticles in the Rhine River. Environmental Science \& Technology 46(12): 6705-6713.

Priester, J. H.; Ge, Y.; Mielke, R. E.; Horst, A. M.; Moritz, S. C.; Espinosa, K.; Gelb, J.; Walker, S. L.; Nisbet, R. M.; An, Y. J.; Schimel, J. P.; Palmer, R. G.; Hernandez-Viezcas, J. A.; Zhao, L. J.; Gardea-Torresdey, J. L.; Holden, P. A. (2012). Soybean susceptibility to manufactured nanomaterials with evidence for food quality and soil fertility interruption. Proceedings of the National Academy of Sciences of the United States of America 109(37): E2451-E2456.

Quicker, P.; Stockschläder, J. (2017). Neue problematische Einsatzstoffe in der Abfallverbrennung (in German). . Thome-Kozmiensky K.J., Beckmann M. Energie aus Abfall, Band 14, TK Verlag Karl Thome-Kozmiensky, Neuruppin, p.41-60.

Quik, J. T. K.; Stuart, M. C.; Wouterse, M.; Peijnenburg, W.; Hendriks, A. J.; van de Meent, D. (2012). Natural colloids are the dominant factor in the sedimentation of nanoparticles. Environmental Toxicology and Chemistry 31(5): 1019-1022.

Quik, J. T. K.; Velzeboer, I.; Wouterse, M.; Koelmans, A. A.; van de Meent, D. (2014). Heteroaggregation and sedimentation rates for nanomaterials in natural waters. Water Research 48(0): 269-279.

Radniecki, T. S.; Stankus, D. P.; Neigh, A.; Nason, J. A.; Semprini, L. (2011). Influence of liberated silver from silver nanoparticles on nitrification inhibition of Nitrosomonas europaea. Chemosphere 85(1): 43-49.

Ramos, M.; Fortunati, E.; Peltzer, M.; Dominici, F.; Jiménez, A.; Garrigós, M. d. C.; Kenny, J. M. (2014). Influence of thymol and silver nanoparticles on the degradation of poly(lactic acid) based nanocomposites: Thermal and morphological properties. Polymer Degradation and Stability 108: 158-165.

Ratte, H. T. (1999). Bioaccumulation and toxicity of silver compounds: A review. Environmental Toxicology and Chemistry 18(1): 89-108.

Ray, S. S.; Yamada, K.; Okamoto, M.; Ogami, A.; Ueda, K. (2003a). New polylactide/layered silicate nanocomposites. 3. High-performance biodegradable materials. Chemistry of Materials 15(7): 1456-1465. 
Ray, S. S.; Yamada, K.; Okamoto, M.; Ueda, K. (2003b). New polylactide-layered silicate nanocomposites. 2. Concurrent improvements of material properties, biodegradability and melt rheology. Polymer 44(3): 857-866.

Reed, R. B.; Faust, J. J.; Yang, Y.; Doudrick, K.; Capco, D. G.; Hristovski, K.; Westerhoff, P. (2014). Characterization of nanomaterials in metal colloid-containing dietary supplement drinks and assessment of their potential interactions after ingestions. Acs Sustainable Chemistry \& Engineering 2(7): 1616-1624.

Regulation (EC) No 1223/2009 Regulation (EC) No 1223/2009 of the European Parliament and of the Council of 30 November 2009 on cosmetic products (Text with EEA relevance).

Reinhart, D.; Bolyard, S. C.; Berge, N. (2016). Grand Challenges - Management of municipal solid waste. Waste Management 49: 1-2.

Reinhart, D. R.; Berge, N. D.; Santra, S.; Bolyard, S. C. (2010). Emerging contaminants: Nanomaterial fate in landfills. Waste Management 30(11): 2020-2021.

Rejeski, D. (2009). "Nanotechnology and consumer products."

Rhiem, S.; Barthel, A.-K.; Meyer-Plath, A.; Hennig, M. P.; Wachtendorf, V.; Sturm, H.; Schäffer, A.; Maes, H. M. (2016). Release of 14C-labelled carbon nanotubes from polycarbonate composites. Environmental Pollution 215: 356-365.

Rocha, T. L.; Mestre, N. C.; Sabóia-Morais, S. M. T.; Bebianno, M. J. (2017). Environmental behaviour and ecotoxicity of quantum dots at various trophic levels: A review. Environment International 98: 1-17.

Saffarzadeh, A.; Shimaoka, T.; Wei, Y.; Gardner, K. H.; Musselman, C. N. (2011). Impacts of natural weathering on the transformation/neoformation processes in landfilled MSWI bottom ash: a geoenvironmental perspective. Waste Manag 31(12): 2440-2454.

Saheli, P. T.; Rowe, R. K.; Petersen, E. J.; O'Carroll, D. M. (2017). Diffusion of multiwall carbon nanotubes through a high-density polyethylene geomembrane. Geosynthetics International 24(2): 184-197.

Sakallioglu, T.; Bakirdoven, M.; Temizel, I.; Demirel, B.; Copty, N. K.; Onay, T. T.; Uyguner Demirel, C. S.; Karanfil, T. (2016). Leaching of nano-ZnO in municipal solid waste. Journal of Hazardous Materials 317: 319-326.

Saleh, N. B.; Pfefferle, L. D.; Elimelech, M. (2010). Influence of Biomacromolecules and Humic Acid on the Aggregation Kinetics of Single-Walled Carbon Nanotubes. Environmental Science \& Technology 44(7): 2412-2418.

Sánchez, C.; Hortal, M.; Aliaga, C.; Devis, A.; Cloquell-Ballester, V. A. (2014). Recyclability assessment of nano-reinforced plastic packaging. Waste Management 34(12): 2647-2655.

Schaumann, G. E.; Philippe, A.; Bundschuh, M.; Metreveli, G.; Klitzke, S.; Rakcheev, D.; Grun, A.; Kumahor, S. K.; Kuhn, M.; Baumann, T.; Lang, F.; Manz, W.; Schulz, R.; Vogel, H. J. (2014). Understanding the fate and biological effects of $\mathrm{Ag}$ - and TiO-nanoparticles in the environment: The quest for advanced analytics and interdisciplinary concepts. Sci Total Environ.

Schlagenhauf, L.; Chu, B. T. T.; Buha, J.; Nüesch, F.; Wang, J. (2012). Release of Carbon Nanotubes from an Epoxy-Based Nanocomposite during an Abrasion Process. Environmental Science \& Technology 46(13): 7366-7372. 
Schlagenhauf, L.; Kianfar, B.; Buerki-Thurnherr, T.; Kuo, Y.-Y.; Wichser, A.; Nuesch, F.; Wick, P.; Wang, J. (2015). Weathering of a carbon nanotube/epoxy nanocomposite under UV light and in water bath: impact on abraded particles. Nanoscale 7(44): 18524-18536.

Schlagenhauf, L.; Nüesch, F.; Wang, J. (2014). Release of Carbon Nanotubes from Polymer Nanocomposites. Fibers 2(2): 108-127.

Schmid, K.; Riediker, M. (2008). Use of Nanoparticles in Swiss Industry: A Targeted Survey. Environmental Science \& Technology 42(7): 2253-2260.

Song, R.; Qin, Y.; Suh, S.; Keller, A. A. (2017). Dynamic Model for the Stocks and Release Flows of Engineered Nanomaterials. Environmental Science \& Technology.

Stamou, I.; Antizar-Ladislao, B. (2016a). The impact of silver and titanium dioxide nanoparticles on the in-vessel composting of municipal solid waste. Waste Management 56: 71-78.

Stamou, I.; Antizar-Ladislao, B. (2016b). A life cycle assessment of the use of compost from contaminated biodegradable municipal solid waste with silver and titanium dioxide nanoparticles. Journal of Cleaner Production 135: 884-891.

Stark, W. J. (2011). Nanoparticles in Biological Systems. Angewandte Chemie International Edition 50(6): 1242-1258.

Stloukal, P.; Pekařová, S.; Kalendova, A.; Mattausch, H.; Laske, S.; Holzer, C.; Chitu, L.; Bodner, S.; Maier, G.; Slouf, M.; Koutny, M. (2015). Kinetics and mechanism of the biodegradation of PLA/clay nanocomposites during thermophilic phase of composting process. Waste Management 42: 31-40.

Struwe, J.; Schindler, E. (2012). Bedeutung von Nanomaterialien beim Recycling von Abfällen. Arbeitspapier 270. Düsseldorf, Hans-Böckler-Stiftung. Mitbestimmungs-, Forschungs- und Studienförderungswerk des DGB.

Sun, T.; Mitrano, D. M.; Bornhöft, N. A.; Scheringer, M.; Hungerbuehler, K.; Nowack, B. (2017). Envisioning nano release dynamics in a changing world: using dynamic probabilistic modelling to assess future environmental emissions of engineered nanoparticles. Environmental Science \& Technology.

Sun, T. Y.; Bornhöft, N. A.; Hungerbühler, K.; Nowack, B. (2016). Dynamic Probabilistic Modeling of Environmental Emissions of Engineered Nanomaterials. Environmental Science \& Technology 50(9): 4701-4711.

Sun, T. Y.; Gottschalk, F.; Hungerbühler, K.; Nowack, B. (2014). Comprehensive probabilistic modelling of environmental emissions of engineered nanomaterials. Environmental Pollution 185: 69-76.

Sun, W.; Luna-Velasco, A.; Sierra-Alvarez, R.; Field, J. A. (2013). Assessing protein oxidation by inorganic nanoparticles with enzyme-linked immunosorbent assay (ELISA). Biotechnology and Bioengineering 110(3): 694-701.

Sung, L.; Stanley, D.; Gorham, J. M.; Rabb, S.; Gu, X.; Yu, L. L.; Nguyen, T. (2015). A quantitative study of nanoparticle release from nanocoatings exposed to UV radiation. Journal of Coatings Technology and Research 12(1): 121-135.

Suryawanshi, A.; Biswal, M.; Mhamane, D.; Gokhale, R.; Patil, S.; Guin, D.; Ogale, S. (2014). Large scale synthesis of graphene quantum dots (GQDs) from waste biomass and their use as an efficient and selective photoluminescence on-off-on probe for $\mathrm{Ag}(+)$ ions. Nanoscale 6(20): 11664-11670. 
Suzuki, S.; Part, F.; Matsufuji, Y.; Huber-Humer, M. (2018a). Modeling the fate and end-of-life phase of engineered nanomaterials in the Japanese construction sector. Waste Management.

Suzuki, S.; Part, F.; Matsufuji, Y.; Huber-Humer, M. (2018b). Modeling the fate and end-of-life phase of engineered nanomaterials in the Japanese construction sector. Waste Management 72: 389-398.

Tejamaya, M.; Romer, I.; Merrifield, R. C.; Lead, J. R. (2012). Stability of citrate, PVP, and PEG coated silver nanoparticles in ecotoxicology media. Environ Sci Technol 46(13): 7011-7017.

Temizel, I.; Emadian, S. M.; Di Addario, M.; Onay, T. T.; Demirel, B.; Copty, N. K.; Karanfil, T. (2017). Effect of nano-ZnO on biogas generation from simulated landfills. Waste Management 63(Supplement C): 18-26.

Throback, I. N.; Johansson, M.; Rosenquist, M.; Pell, M.; Hansson, M.; Hallin, S. (2007). Silver (Ag+) reduces denitrification and induces enrichment of novel nirK genotypes in soil. FEMS Microbiol Lett 270(2): 189-194.

Tong, Z.; Bischoff, M.; Nies, L.; Applegate, B.; Turco, R. F. (2007). Impact of Fullerene (C60) on a Soil Microbial Community. Environmental Science \& Technology 41(8): 2985-2991.

Valsami-Jones, E.; Lynch, I. (2015). How safe are nanomaterials? Science 350(6259): 388.

Vance, M. E.; Kuiken, T.; Vejerano, E. P.; McGinnis, S. P.; Hochella, M. F., Jr.; Rejeski, D.; Hull, M. S. (2015). Nanotechnology in the real world: Redeveloping the nanomaterial consumer products inventory. Beilstein Journal of Nanotechnology 6: 1769-1780.

Vejerano, E. P.; Holder, A. L.; Marr, L. C. (2013). Emissions of Polycyclic Aromatic Hydrocarbons, Polychlorinated Dibenzo-p-Dioxins, and Dibenzofurans from Incineration of Nanomaterials. Environmental Science \& Technology 47(9): 4866-4874.

Vejerano, E. P.; Leon, E. C.; Holder, A. L.; Marr, L. C. (2014). Characterization of particle emissions and fate of nanomaterials during incineration. Environmental Science: Nano 1(2): 133-143.

Wagner, S.; Gondikas, A.; Neubauer, E.; Hofmann, T.; von der Kammer, F. (2014). Spot the Difference: Engineered and Natural Nanoparticles in the Environment-Release, Behavior, and Fate. Angewandte Chemie International Edition 53(46): 12398-12419.

Walser, T.; Gottschalk, F. (2014). Stochastic fate analysis of engineered nanoparticles in incineration plants. Journal of Cleaner Production 80: 241-251.

Walser, T.; Limbach, L. K.; Brogioli, R.; Erismann, E.; Flamigni, L.; Hattendorf, B.; Juchli, M.; Krumeich, F.; Ludwig, C.; Prikopsky, K.; Rossier, M.; Saner, D.; Sigg, A.; Hellweg, S.; Gunther, D.; Stark, W. J. (2012). Persistence of engineered nanoparticles in a municipal solid-waste incineration plant. Nat Nano 7(8): 520-524.

Wang, Y.; Westerhoff, P.; Hristovski, K. D. (2012). Fate and biological effects of silver, titanium dioxide, and C-60 (fullerene) nanomaterials during simulated wastewater treatment processes. Journal of Hazardous Materials 201: 16-22.

Weir, A.; Westerhoff, P.; Fabricius, L.; Hristovski, K.; von Goetz, N. (2012). Titanium Dioxide Nanoparticles in Food and Personal Care Products. Environmental Science \& Technology 46(4): 2242-2250.

Westerhoff, P. K.; Kiser, M. A.; Hristovski, K. (2013). Nanomaterial Removal and Transformation During Biological Wastewater Treatment. Environmental Engineering Science 30(3): 109-117. 
Wigger, H.; Hackmann, S.; Zimmermann, T.; Köser, J.; Thöming, J.; von Gleich, A. (2015). Influences of use activities and waste management on environmental releases of engineered nanomaterials. Science of The Total Environment 535: 160-171.

Wohlleben, W.; Brill, S.; Meier, M. W.; Mertler, M.; Cox, G.; Hirth, S.; von Vacano, B.; Strauss, V.; Treumann, S.; Wiench, K.; Ma-Hock, L.; Landsiedel, R. (2011). On the Lifecycle of Nanocomposites: Comparing Released Fragments and their In-Vivo Hazards from Three Release Mechanisms and Four Nanocomposites. Small 7(16): 2384-2395.

Wohlleben, W.; Kuhlbusch, T. A. J.; Schnekenburger, J.; Lehr, C.-M. (2014). Safety of Nanomaterials along Their Lifecycle: Release, Exposure, and Human Hazards, CRC Press.

Xanthos, M. (2010). Functional Fillers for Plastics. By Marino Xanthos (Ed.), WILEY-VCH Verlag

Xia, T.; Kovochich, M.; Liong, M.; Mädler, L.; Gilbert, B.; Shi, H.; Yeh, J. I.; Zink, J. I.; Nel, A. E. (2008). Comparison of the Mechanism of Toxicity of Zinc Oxide and Cerium Oxide Nanoparticles Based on Dissolution and Oxidative Stress Properties. ACS Nano 2(10): 2121-2134.

Xu, X.-H. N.; Brownlow, W. J.; Kyriacou, S. V.; Wan, Q.; Viola, J. J. (2004). Real-Time Probing of Membrane Transport in Living Microbial Cells Using Single Nanoparticle Optics and Living Cell Imaging. Biochemistry 43(32): 10400-10413.

Yang, X.; Zhang, Y.; Chen, F.; Yang, Y. (2015). Interplay of Natural Organic Matter with Flow Rate and Particle Size on Colloid Transport: Experimentation, Visualization, and Modeling. Environmental Science \& Technology 49(22): 13385-13393.

Yang, Y.; Doudrick, K.; Bi, X.; Hristovski, K.; Herckes, P.; Westerhoff, P.; Kaegi, R. (2014a). Characterization of food-grade titanium dioxide: The presence of nanosized particles. Environmental Science \& Technology 48(11): 6391-6400.

Yang, Y.; Gajaraj, S.; Wall, J. D.; Hu, Z. (2013). A comparison of nanosilver and silver ion effects on bioreactor landfill operations and methanogenic population dynamics. Water Res 47(10): 3422-3430.

Yang, Y.; Wang, Y.; Westerhoff, P.; Hristovski, K.; Jin, V. L.; Johnson, M.-V. V.; Arnold, J. G. (2014b). Metal and nanoparticle occurrence in biosolid-amended soils. Science of The Total Environment 485-486: 441-449.

Yang, Y.; Westerhoff, P. (2014). Presence in, and Release of, Nanomaterials from Consumer Products. Nanomaterial. D. G. Capco and Y. Chen, Springer Netherlands. 811: 1-17.

Yang, Y.; Xu, M.; Wall, J. D.; Hu, Z. (2012). Nanosilver impact on methanogenesis and biogas production from municipal solid waste. Waste Management 32(5): 816-825.

Yazici Guvenc, S.; Alan, B.; Adar, E.; Bilgili, M. S. (2017). The impact of nanoparticles on aerobic degradation of municipal solid waste. Waste Management \& Research 35(4): 426-436.

Yokoyama, T. (2012). Chapter 1 - Basic properties and measuring methods of nanoparticles A2 Hosokawa, Masuo. Nanoparticle Technology Handbook (Second Edition). K. Nogi, M. Naito and T. Yokoyama. Amsterdam, Elsevier: 3-48.

Yu, R.; Fang, X.; Somasundaran, P.; Chandran, K. (2015). Short-term effects of TiO2, CeO2, and ZnO nanoparticles on metabolic activities and gene expression of Nitrosomonas europaea. Chemosphere 128: 207-215. 
1707

1708

1709

1710

1723
Zhang, H.; Bussini, D.; Hortal, M.; Elegir, G.; Mendes, J.; Jordá Beneyto, M. (2016). PLA coated paper containing active inorganic nanoparticles: Material characterization and fate of nanoparticles in the paper recycling process. Waste Management 52: 339-345.

Zhang, L.; Zeng, G.; Dong, H.; Chen, Y.; Zhang, J.; Yan, M.; Zhu, Y.; Yuan, Y.; Xie, Y.; Huang, Z. (2017). The impact of silver nanoparticles on the co-composting of sewage sludge and agricultural waste: Evolutions of organic matter and nitrogen. Bioresource Technology 230: 132-139.

Zhang, Y.; Leu, Y.-R.; Aitken, R.; Riediker, M. (2015). Inventory of engineered nanoparticle-containing consumer products available in the Singapore retail market and likelihood of release into the aquatic environment. International Journal of Environmental Research and Public Health 12(8): 8717.

Zheng, X.; Chen, Y.; Wu, R. (2011). Long-Term Effects of Titanium Dioxide Nanoparticles on Nitrogen and Phosphorus Removal from Wastewater and Bacterial Community Shift in Activated Sludge. Environmental Science \& Technology 45(17): 7284-7290.

Zhou, D.; Ji, Z.; Jiang, X.; Dunphy, D. R.; Brinker, J.; Keller, A. A. (2013). Influence of material properties on TiO2 nanoparticle agglomeration. PLoS One 8(11): e81239.

Zhuo, C.; Levendis, Y. A. (2014). Upcycling waste plastics into carbon nanomaterials: A review. Journal of Applied Polymer Science 131(4): n/a-n/a.

Zuin, S.; Gaiani, M.; Ferrari, A.; Golanski, L. (2013). Leaching of nanoparticles from experimental water-borne paints under laboratory test conditions. Journal of Nanoparticle Research 16(1): 2185.

Zuin, S.; Massari, A.; Ferrari, A.; Golanski, L. (2014). Formulation effects on the release of silica dioxide nanoparticles from paint debris to water. Science of The Total Environment 476: 298-307. 


\begin{tabular}{|c|c|c|c|c|c|}
\hline ENM Type & $\begin{array}{l}\text { Molecular } \\
\text { Formula }\end{array}$ & Occurrence $^{*}$ & $\begin{array}{l}\text { Global } \\
\text { Consumption [t/a] }\end{array}$ & $\begin{array}{l}\text { Market value } \\
\quad[\text { Mio } €]\end{array}$ & Applications \\
\hline \multicolumn{6}{|c|}{ Metals and metal oxides } \\
\hline \multirow{4}{*}{$\begin{array}{l}\text { synthetic amorphous silica, } \\
\text { including precipitated silica, silica } \\
\text { gels, colloidal silica or silica sols } \\
\text { and fumed or pyrogenic silica }\end{array}$} & $\mathrm{SiO}_{2}$ & $\begin{array}{l}\text { in bulk and nanoform as powders } \\
\text { or colloidal dispersions }\end{array}$ & 1.5 million & 2700 & \\
\hline & & colloidal silica & & & $\begin{array}{l}\text { paper industry, processing industry (e.g., as polish } \\
\text { agent), metallurgy, food industry, building industry } \\
\text { and polymer industry }\end{array}$ \\
\hline & & precipitated silica & & & $\begin{array}{l}\text { plastic industry (e.g., tyres, footwear and other rubber } \\
\text { articles), food industry, paper industry }\end{array}$ \\
\hline & & $\begin{array}{l}\text { silica gels } \\
\text { pyrogenic (fumed) silica }\end{array}$ & & & $\begin{array}{l}\text { food industry, health industry, cosmetic industry } \\
\text { food industry, cosmetic industry }\end{array}$ \\
\hline Titanium dioxide powder & $\mathrm{TiO}_{2}$ & $\begin{array}{l}\text { in bulk and nanoform as powders } \\
\text { or wires; in crystalline, rutile and } \\
\text { anatase modifications }\end{array}$ & 10 million & n.n. & $\begin{array}{l}\text { cosmetic industry, building industry, textile industry, } \\
\text { electronic industry }\end{array}$ \\
\hline Zinc oxide powder & $\mathrm{ZnO}$ & in bulk and nanoform as powders & $>1000$ & n.n. & $\begin{array}{l}\text { cosmetic industry, paint and varnish industry, } \\
\text { ceramic, electronic and plastic industry }\end{array}$ \\
\hline Aluminium oxide & $\mathrm{Al}_{2} \mathrm{O}_{3}$ & $\begin{array}{l}\text { in bulk and nanoform as powders } \\
\text { or in dispersions }\end{array}$ & 0.2 million & 750 & $\begin{array}{l}\text { processing industry (e.g., for grinding tools, as } \\
\text { polishing agent), automobile industry, electronic } \\
\text { industry, ceramic industry, plastic industry }\end{array}$ \\
\hline $\begin{array}{l}\text { Aluminium hydroxides and } \\
\text { aluminium oxo-hydroxides }\end{array}$ & $\mathrm{Al}(\mathrm{OH})_{3}, \mathrm{AlO}(\mathrm{OH})$ & $\begin{array}{l}\text { in bulk and nanoform as powders } \\
\text { or in dispersions; as e.g., gibbsite } \\
\left(\mathrm{\gamma}-\mathrm{Al}(\mathrm{OH})_{3}\right) \text {, bayerite }\left(\mathrm{\alpha}-\mathrm{Al}(\mathrm{OH})_{3}\right) \\
\text { boehmite }(\mathrm{Y}-\mathrm{AlO}(\mathrm{OH})) \text { or diaspore } \\
(\mathrm{\alpha}-\mathrm{AlO}(\mathrm{OH}))\end{array}$ & n.n. & n.n. & plastic industry, dye industry \\
\hline $\begin{array}{l}\text { Iron(II) oxide, iron(III)oxide and } \\
\text { zerovalent iron }\end{array}$ & $\mathrm{Fe}_{2} \mathrm{O}_{3}, \mathrm{Fe}_{3} \mathrm{O}_{4} \mathrm{Fe}^{0}$ & $\begin{array}{l}\text { in bulk and nanoform as powders } \\
\text { or in dispersions; often as } \\
\text { hematite }\left(\mathrm{Fe}_{2} \mathrm{O}_{3}\right) \text { or magetite } \\
\left(\mathrm{Fe}_{3} \mathrm{O}_{4}\right)\end{array}$ & 100 & $20-40$ & $\begin{array}{l}\text { automotive and cosmetic industry, electronic industry, } \\
\text { medical use, "green" industry }\end{array}$ \\
\hline $\begin{array}{l}\text { Cerium dioxide } \\
\text { Zirconium dioxide }\end{array}$ & $\begin{array}{l}\mathrm{CeO}_{2} \\
\mathrm{ZrO}_{2}\end{array}$ & $\begin{array}{l}\text { in bulk and nanoform as powders } \\
\text { in bulk and nanoform as powders }\end{array}$ & $\begin{array}{c}10 \\
2500-3000\end{array}$ & $\begin{array}{l}\text { n.n. } \\
\text { n.n. }\end{array}$ & $\begin{array}{l}\text { processing, automotive and construction industry } \\
\text { electronic industry (e.g., in optical connectors), } \\
\text { processing industry (e.g., in batteries, fuel cells, } \\
\text { ceramics, catalysts, fluorescent lightings, polishing } \\
\text { agents), medical use (e.g., dental fillings, biomedical } \\
\text { implants) }\end{array}$ \\
\hline $\begin{array}{l}\text { other oxide nanomaterials (e.g., } \\
\text { indium tin oxide (ITO) antimony tin } \\
\text { oxide (ATO), barium titanate and } \\
\text { other rare earth oxides) }\end{array}$ & $\begin{array}{c}\mathrm{In}_{2} \mathrm{O}_{3} / \mathrm{SnO}_{2} \\
\mathrm{SnO}_{2} / \mathrm{Sb}_{2} \mathrm{O}_{5} \text { or } \\
\mathrm{BaTiO}_{3}\end{array}$ & nanoform as powders & $>15000$ & n.n. & $\begin{array}{l}\text { electronic industry (e.g.,, organic LEDs, touch } \\
\text { screens, thin-film solar cells, sensors), construction } \\
\text { industry (e.g., in thermal isolating windows) }\end{array}$ \\
\hline Calcium Carbonate & $\mathrm{CaCO}_{3}$ & in bulk and nanoform as powders & & n.n. & $\begin{array}{l}\text { plastic industry (e.g., as filler in window frames or } \\
\text { paints or as sealant), paper industry (e.g., as filler), in } \\
\text { food industry (e.g., as additive) }\end{array}$ \\
\hline
\end{tabular}


metal (aluminium, silicon, nitrides, carbides an

Gold

AIN, $\mathrm{Si}_{3} \mathrm{~N}_{4}, \mathrm{TiN}$ TiCN, WC, $\mathrm{WS}_{2}$ dispersions

004

in bulk and nanoform as powders, wires or stable dispersions
CdSe, CdS, PbS, in nanoform as powders or stable InAs, InP etc. dispersions

Core-shell nanocrystals or quantum dots (cadmium selenide, cadmium sulphide, cadmium telluride, lead sulphide, indium arsenide, indium phosphide etc. Other metals and alloys (e.g. lithium, titanium, iron, copper, molybdenum, rhodium, platinum, lanthanum, neodymium etc.)

\section{Fullerenes}

, Ti, $\mathrm{Fe}, \mathrm{Co}, \mathrm{Mo}, \quad$ in bulk and nanoform $\mathrm{Rh}, \mathrm{Pt}, \mathrm{La}, \mathrm{Nd}$ etc. also as, e.g., titania paste

$\mathrm{C}_{60}, \mathrm{C}_{70}$ etc. in nanoform as powders

\section{arbon-based nanomaterials}

tubes: $200-250$, fibers: $300-350$

ubes: $30-40$

in nanoform as powders (e.g., tubes or fibers) or stable dispersions

Carbon

in bulk and nanoform

9.6 million
Carbon in bulk (e.g.,graphene oxide) and n.n.

Carbon in bulk (e.g.,graphene oxide) and n.n. nanoform as atom thick monolayers on varying substrates or as flakes in dispersions

Nanopolymers, dendrimers and other nanomaterials

Nano-objects (e.g., nanocellulose n.n. $n+n$ $n$. n.n.

n. $n$ processing industry (e.g., as additive in metal alloys or plastic)

medical use (e.g., for diagnostic), research and development (e.g., as standard reference material in chemical analysis), electronic industry (e.g., as semiconductor)

textile industry (e.g., in, wound plasters, socks, underwear), plastic industry (e.g., in, toys, washing machine, paints), cosmetic industry, electronic

industry (e.g., in, antimicrobial coatings,

photovoltaics, displays)

research and development (e.g., as biomarkers or for . industry (e.g., in solar cells, LEDs, photodetectors)

electronic industry (e.g., as semi-conductor), processing industry (e.g., as catalyst)

plastic industry (e.g., as, additives in sports equipment), electronic industry (e.g., in, solar cells battery anodes), cosmetic industry, medical use plastic industry (e.g., as additives, in textiles, casings, sports equipment, paints) electronic industry (e.g., in, solar cells, membranes for batteries, electrodes, conductive inks), cosmetic industry, medical use (e.g., bone tissue engineering), "green" industry plastic industry (e.g., as filler in composite materials) electronic industry (e.g., in, electrodes, toners or inks), cosmetic industry

electronic industry (e.g., as, sensors, transistors, circuits, electrodes, solar and fuel cells), automotive industry, aircraft industry

dendrimers and other polymer

n.n.

research and development, electronic industry, medical use

nano-structures materials (e.g

polymer films)

* information is based on material safety data sheet (MSDS), available at Sigma-Aldrich Co. LLC 
Table 2. Sources of ENM in biological treatment operations.

\begin{tabular}{|c|c|c|}
\hline ENM Source & Investigated ENM types & Source \\
\hline Textiles & Ag, CNTs & $\begin{array}{l}\text { (Benn et al. 2010; Benn and Westerhoff 2008a; Zhang et } \\
\text { al. 2015) }\end{array}$ \\
\hline Food Packaging & $\mathrm{SiO}_{2}, \quad \mathrm{CNT}$ & $\begin{array}{l}\text { (Center for food safety 2014; Llorens et al. 2012; Zhang } \\
\text { et al. 2015) }\end{array}$ \\
\hline $\begin{array}{l}\text { Food and } \\
\text { Beverages }\end{array}$ & $\begin{array}{l}\mathrm{Al}_{2} \mathrm{O}_{3}, \mathrm{Fe} / \mathrm{Fe}_{\mathrm{x}} \mathrm{O}_{\mathrm{y}} \text {, ceramics, } \\
\mathrm{TiO}_{2} \mathrm{Aq} . \mathrm{Fe}\end{array}$ & $\begin{array}{l}\text { (Blasco and Picó 2011; Reed et al. 2014; Weir et al. } \\
\text { 2012; Yang et al. 2014a: Zhang et al. 2015) }\end{array}$ \\
\hline $\begin{array}{l}\text { Biosolids (sewage } \\
\text { sludges) }\end{array}$ & $\mathrm{TiO}_{2}, \mathrm{Ag}, \mathrm{ZnO}, \mathrm{SiO}_{2}, \mathrm{C}_{60}$ & $\begin{array}{l}\text { (Kiser et al. 2009; Wang et al. 2012; Westerhoff et al. } \\
2013 \text { ) }\end{array}$ \\
\hline
\end{tabular}


Table 3. Studies evaluating the influence of ENM presence on biological treatment of MSW under aerobic conditions.

\begin{tabular}{|c|c|c|c|c|c|}
\hline Waste Material & Composting conditions & ENM Used & $\begin{array}{l}\text { ENM concentration } \\
\text { ( } \mathrm{mg} / \mathrm{kg} \text { solid) }\end{array}$ & $\begin{array}{l}\text { Reported Impact on Composting } \\
\text { Processes }\end{array}$ & Reference \\
\hline Simulated food wastes & $\begin{array}{l}\text { - Waste was spiked with } \\
\text { ENMs } \\
\text { - Aerobically composted } \\
\text { over a } 60 \text {-day period at } \\
50^{\circ} \mathrm{C} \text { and a moisture } \\
\text { content of } 65 \%(\mathrm{w} / \mathrm{w})\end{array}$ & $\begin{array}{l}\text { - Polyvinylpyrrolidone } \\
\text { (PVP)-Ag }\end{array}$ & - $2 \mathrm{mg} \mathrm{Ag} / \mathrm{kg}$ compost & $\begin{array}{l}\text { - Nano-Ag did not influence the solid, } \\
\text { liquid, or gas quality parameters and } \\
\text { thus overall composting performance } \\
\text { - The presence of nano-Ag did result in } \\
\text { changes in bacterial community } \\
\text { structure }\end{array}$ & $\begin{array}{l}\text { Gitipour et } \\
\text { al. (2013) }\end{array}$ \\
\hline $\begin{array}{l}\text { Artificial MSW } \\
\text { consisting of: leaves, } \\
\text { grass, wheat straw, } \\
\text { saw dust, and food }\end{array}$ & $\begin{array}{l}\text { - Artificial waste was } \\
\text { spiked with dispersion of } \\
\text { ENMs } \\
\text { - Waste was composted at } \\
38^{\circ} \mathrm{C} \text { with an continuous } \\
\text { air addition }\end{array}$ & $\begin{array}{l}\text { - Commercially } \\
\text { doped } \mathrm{Ag}-\mathrm{TiO}_{2} \\
\text { - } \mathrm{Ag}\end{array}$ & $\begin{array}{l}\text { - } \mathrm{Ag}-\mathrm{TiO}_{2}: 5-50 \mathrm{mg} \\
\mathrm{Ag} / \mathrm{kg} \text { organic matter } \\
\text { and } 225-2,250 \mathrm{mg} \\
\mathrm{Ti} / \mathrm{kg} \text { organic matter } \\
\text { - } \mathrm{Ag}: 5-50 \mathrm{mg} \mathrm{Ag} / \mathrm{kg} \\
\text { organic matter }\end{array}$ & $\begin{array}{l}\text { - Presence of ENMs may influence } \\
\text { composting processes, but do not } \\
\text { affect the functionality of the process } \\
\text { - Waste degradation was not inhibited } \\
\text { in the presence of the ENMs }\end{array}$ & $\begin{array}{l}\text { Stamou and } \\
\text { Antizar-Ladi } \\
\text { slao (2016a) }\end{array}$ \\
\hline $\begin{array}{l}\text { Sewage sludge, rice } \\
\text { straw, vegetables, and } \\
\text { bran }\end{array}$ & $\begin{array}{l}\text { - Sewage sludge and other } \\
\text { waste constituents were } \\
\text { spiked with PVP-Ag } \\
\text { - Composted for } 60 \text { days } \\
\text { and turned once per day }\end{array}$ & $\begin{array}{l}\text { - Polyvinylpyrrolidone } \\
\text { (PVP)-Ag }\end{array}$ & - $2 \mathrm{mg} / \mathrm{kg}$ compost & $\begin{array}{l}\text { - Nano-Ag may impede organic matter } \\
\text { decomposition } \\
\text { - Nano-Ag may reduce losses of total } \\
\text { nitrogen, but increases the loss of } \\
\text { mineral nitrogen }\end{array}$ & $\begin{array}{l}\text { Zhang et al. } \\
(2017)\end{array}$ \\
\hline
\end{tabular}


Table 4. List of knowledge gaps and research questions associated with ENM fate during waste management processes.

\begin{tabular}{|c|c|}
\hline $\begin{array}{c}\text { Waste } \\
\text { Management Process }\end{array}$ & Knowledge Gap/Research Questions \\
\hline Waste generation & $\begin{array}{l}\text { - How can we design "safe" and recyclable ENMs used for consumer products? } \\
\text { - What is the composition and specification of ENMs found in consumer products } \\
\text { following their active life phase? } \\
\text {-What mass of ENMs is distributed in waste management systems and, particularly, } \\
\text { accumulates in landfills? }\end{array}$ \\
\hline $\begin{array}{l}\text { Waste ageing during } \\
\text { processing/treatment }\end{array}$ & $\begin{array}{l}\text {-What do released ENMs from consumer products consist of (e.g., discrete particles, } \\
\text { aggregates, particles embedded within the parent product matrix)? } \\
\text { - What mechanical, biological, and/or chemical processes are most influential during } \\
\text { ENM release from consumer products? } \\
\text { - How does consumer product degradation influence the release of ENMs? }\end{array}$ \\
\hline $\begin{array}{l}\text { Biological waste } \\
\text { treatment (composting } \\
\text { or biogas production) }\end{array}$ & $\begin{array}{l}\text { - At what concentration do ENMs influence waste degradation during composting } \\
\text { and/or biogas production and does this concentration level differ for different } \\
\text { ENMs? } \\
\text { - How do factors such as moisture content and aeration rate influence ENM fate? } \\
\text { - How does ENM surface chemistry (e.g., coated, uncoated) influence waste } \\
\text { degradation? } \\
\text { - How does ENM surface chemistry (e.g., coated, uncoated) influence waste ENM } \\
\text { fate? } \\
\text { - At what levels can ENM-containing compost or biosolids be land applied without } \\
\text { resulting in adverse environmental impacts? }\end{array}$ \\
\hline Recycling & $\begin{array}{l}\text { - Which mechanisms trigger ENM release and mobility during recycling processes? } \\
\text { - How to quantify nanoemissions during physical or chemical treatment? } \\
\text { - Do ENMs decrease the product quality of recyclables? } \\
\text { - Which nanotechnology-based methods allow for improving recycling efficiency? }\end{array}$ \\
\hline Incineration & $\begin{array}{l}\text { - Which combustion technology provides the "safest" ENM-containing waste } \\
\text { treatment method? } \\
\text { - Can all types of organic ENMs be eliminated during combustion? } \\
\text { - Are all metallic ENMs thermally stable under realistic conditions? } \\
\text { - Is there an adverse effect of ENMs on the recyclability of solid residues? }\end{array}$ \\
\hline Landfilling & $\begin{array}{l}\text { - Do ENMs have an adverse impact on microbial activity in landfills? } \\
\text { - What are the main mechanisms triggering ENM release and transfer from solid } \\
\text { matrices to the leachate stream? } \\
\text { - How significant is ENM mobility through landfills, especially those in which no } \\
\text { barrier system exists? } \\
\text { - How can ENM deposition/attachment efficiency be determined for different types of } \\
\text { landfilled waste? } \\
\text { - What is the fate of ENMs during leachate treatment processes? } \\
\text { to quantify ENM transformation, particularly aggregation, as well as to determine } \\
\text { particle size distribution and shape in complex landfill leachates? }\end{array}$ \\
\hline
\end{tabular}




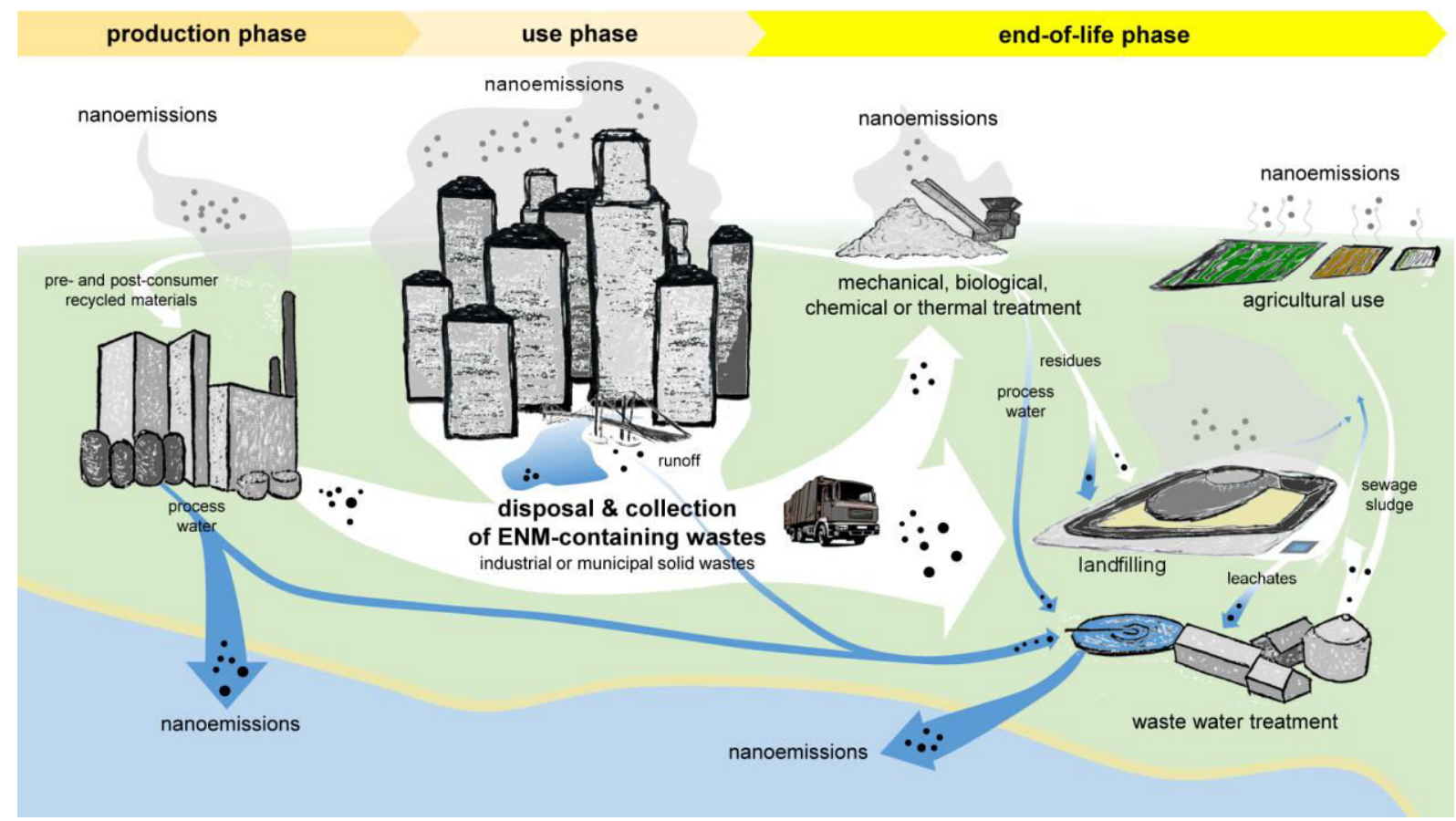

Figure 1. Potential sources for ENM-containing wastes and nanoemissions at different stages during the life cycle 
ENMs in consumer products

ENM production

oo
D.
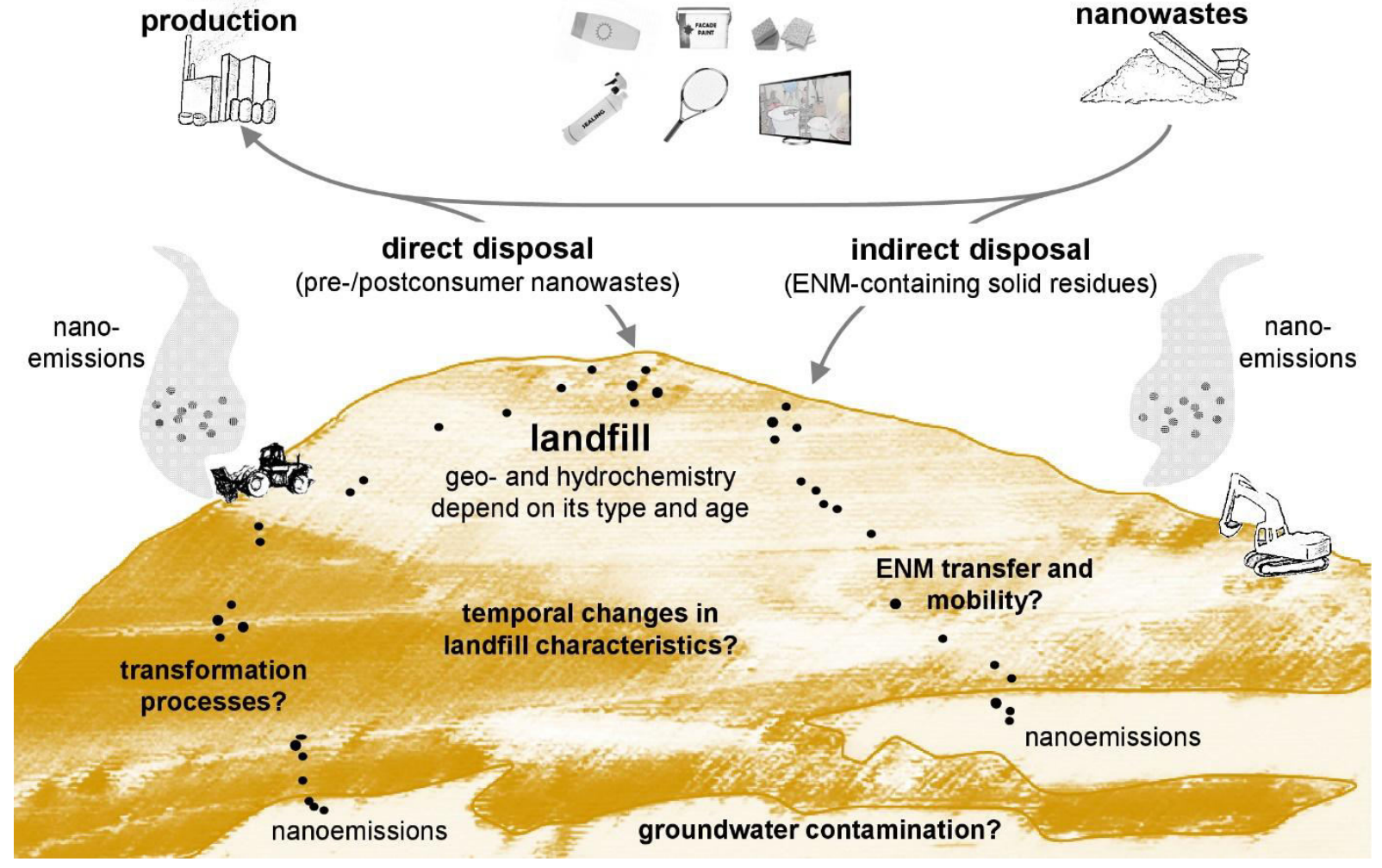

pre-/treatment of nanowastes

Figure 2. Potential entry points and emission pathways of ENMs into and out of landfills. 

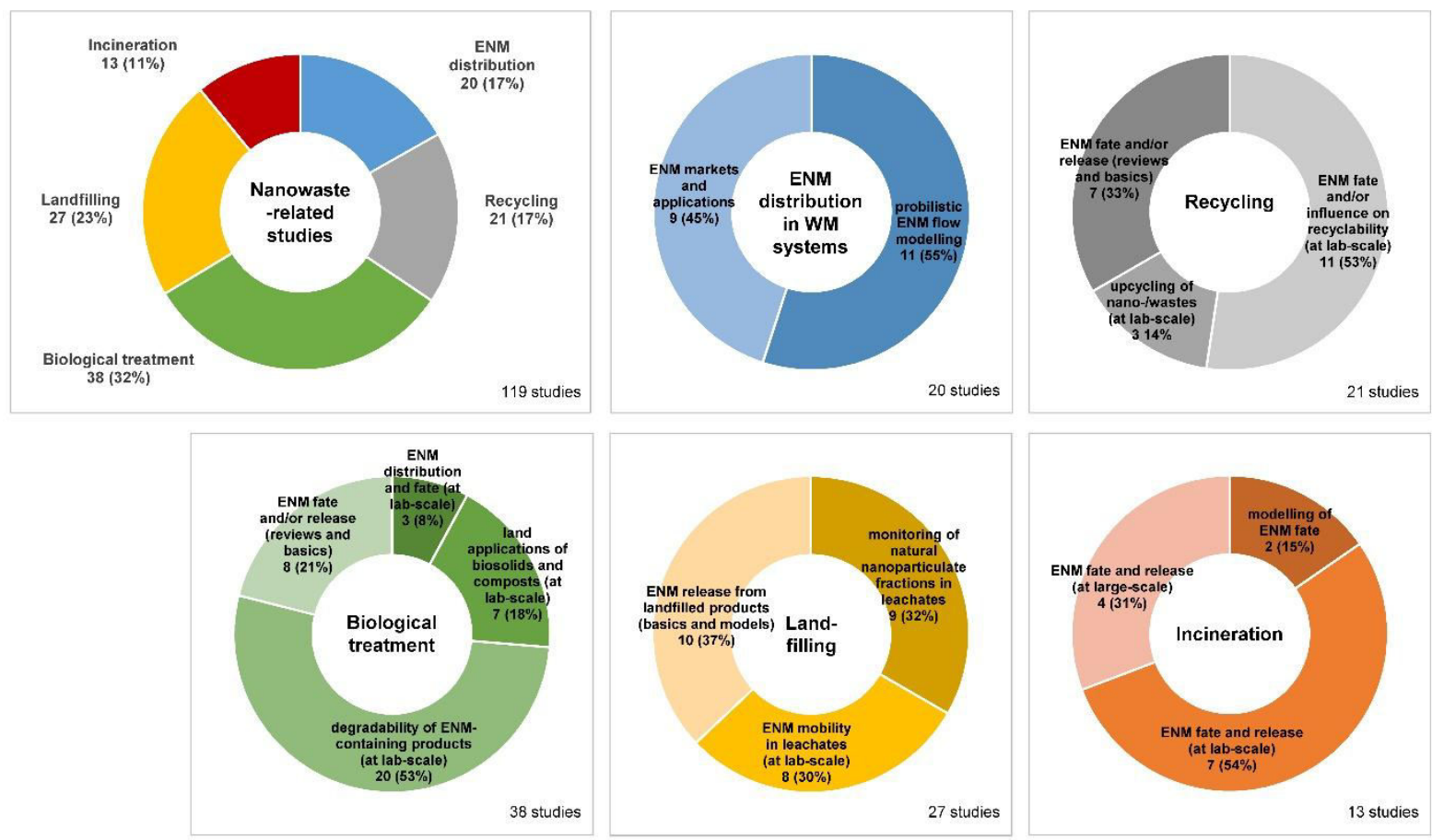

Figure 3. Summary of reviewed studies addressing ENM-containing wastes and their potential implications.

1824 

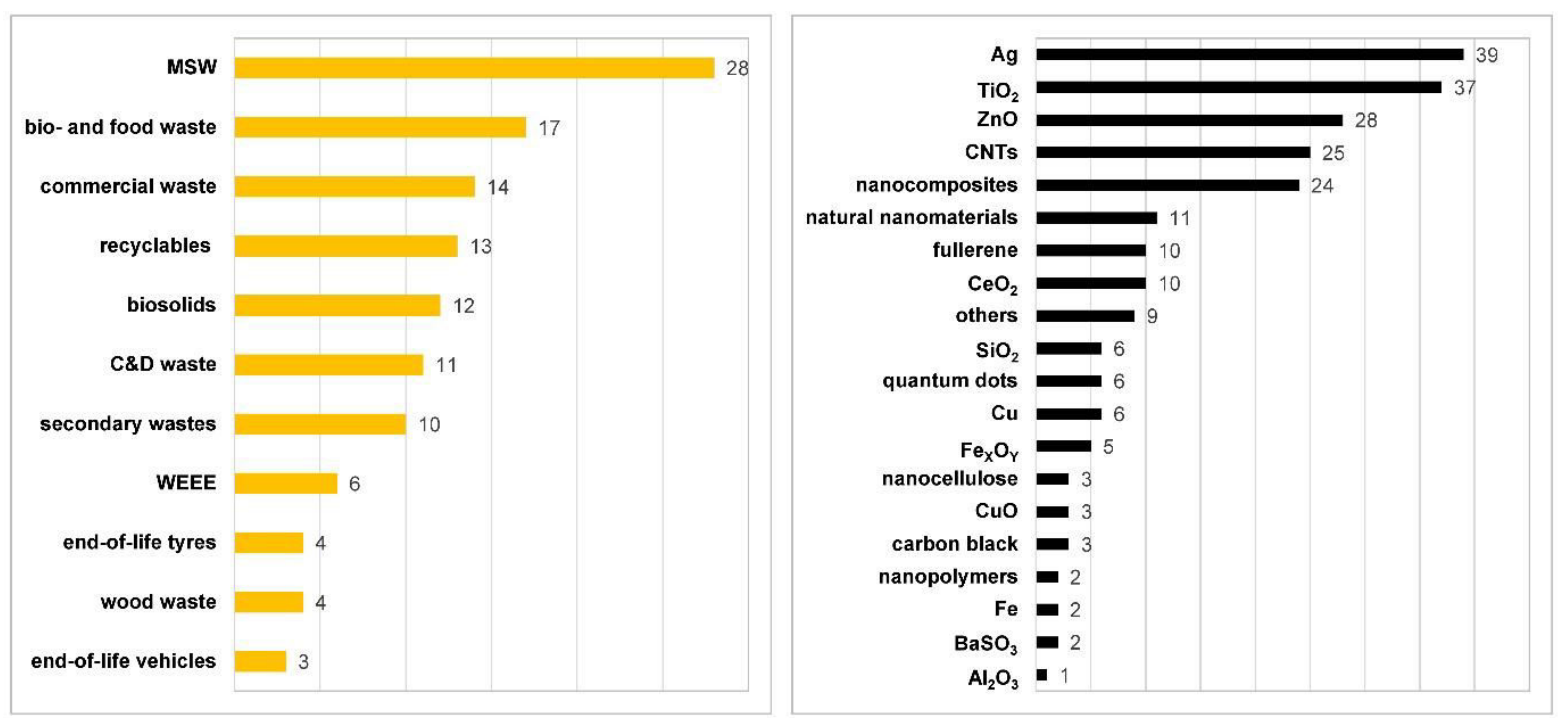

Figure 4. Listed waste streams and ENM types that were of interest in the framework of the 117 reviewed studies 1833 about ENM-containing wastes. 